\title{
Weakening and Rupture of Human Fetal Membranes - Biochemistry and Biomechanics
}

\author{
N. Rangaswamy ${ }^{1}$, D. Kumar ${ }^{1}$, R.M. Moore ${ }^{1}$, \\ B.M. Mercer2, J.M. Mansour ${ }^{3}$, R. Redline ${ }^{4}$ and J.J. Moore ${ }^{1,2}$ \\ ${ }^{1}$ Department of Pediatrics, \\ ${ }^{2}$ Department of Reproductive Biology, \\ ${ }^{3}$ Department of Mechanical and Aerospace Engineering, \\ ${ }^{4}$ Department of Pathology, Case Western Reserve University, Cleveland, $\mathrm{OH}$, \\ USA
}

\section{Introduction}

In spite of advances in the quality of prenatal care, management of high-risk pregnancies and treatment strategies targeting prevention of preterm births, the rate of preterm births in the US has continued to rise over the last two decades and is associated with high mortality and morbidity. Care of preterm infants also poses a significant financial burden on limited health care resources. Infants born at less than 37 weeks gestation account for $69 \%$ of all US infant deaths and their care has been modestly estimated at 26 billion dollars per year (Behrman et al., 2006; MacDorman et al., 2008). Preterm Premature Rupture of Membranes (PPROM) causes $30-40 \%$ of all preterm births and is disproportionately distributed such that African Americans suffer twice the rate of PPROM than Caucasians (Goldenberg et al., 1996a). Although some limited success has been achieved in the treatment of iatrogenic fetal membrane (FM) rupture resulting from amniocentesis or fetal surgery (Quintero et al., 1999; Young et al., 2000; O'Brien et al., 2001; Bilic et al., 2010), there has been no success in the repair of spontaneously ruptured FM, as occurs with PPROM (Quintero et al., 1998; Sciscione et al., 2001; Young et al., 2004b; Devlieger et al., 2006). Recent progress in the understanding of the biochemically-mediated processes which lead to FM weakening and rupture suggests that inhibition of these processes may be possible. This generates hope that many cases of PPROM may ultimately be preventable (R.M. Moore et al., 2009b, 2010; Kumar et al., 2011).

\section{New techniques used in the studies on FM rupture}

\subsection{Mapping procedure}

We have developed and utilized a systematic procedure to map the rupture strength of FM over its entire topographic surface, thereby identifying relatively weak areas for further biochemical, proteomic, and sophisticated biomechanical testing. 


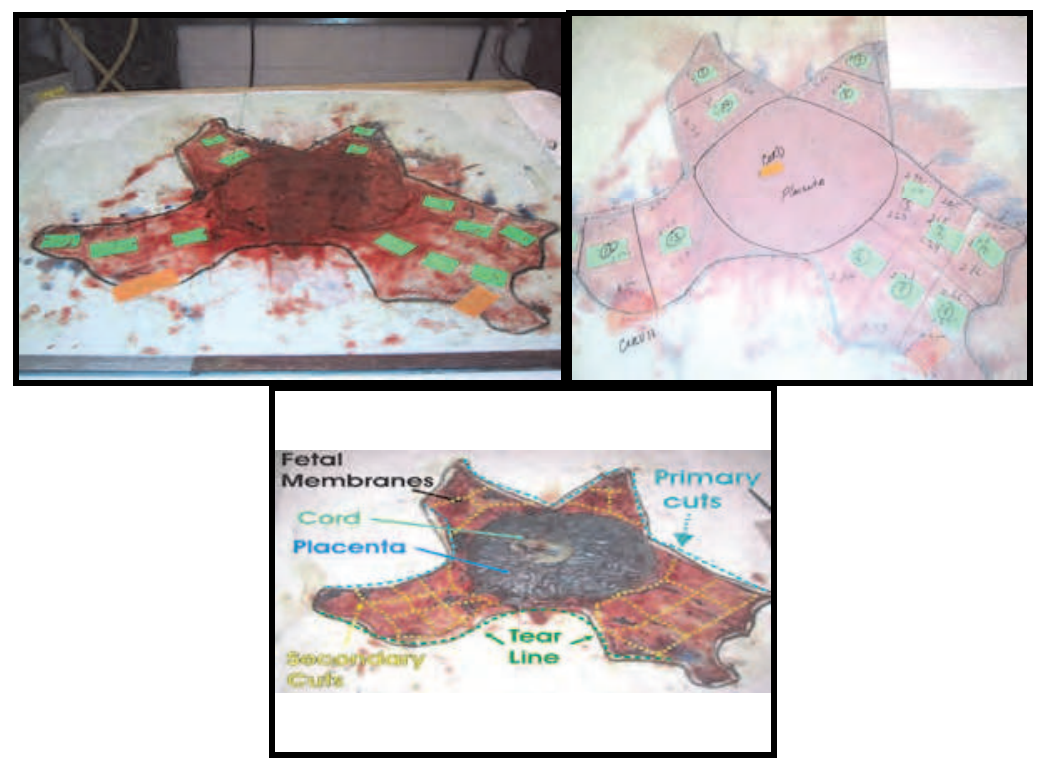

Fig. 1. Fetal Membrane cutting procedure. (Top Left) Marked membranes showing location of primary cuts required to lay the membranes flat. (Top Right) Membrane fragments removed with outlines of pieces on lab table paper. (Bottom) Paper tracing reproduction showing cuts, orientation and location of all pieces, and strength results. (Reproduced with permission from El-Khwad et al. Biol Reprod 72:720-726, 2005.)

Although animal data document homogeneous weakening of the FM over the entire surface with increasing gestation (Lei et al., 1995, 1997; Paavola et al., 1995; Parry et al., 1998), attempts to demonstrate similar gestational changes in human FM were unsuccessful (Manabe et al., 1991). Studies in which whole FM or randomly selected pieces were sampled showed high variability and no definite pattern of remodeling and apoptosis. In response to the challenge of interpreting variable data, we developed a systematic method of cutting the membranes (El-Khwad et al., 2005; Fig. 1.). Fetal membranes to be tested were cut along specific grids. We identified the region of the membranes overlying the cervix by marking it in utero with Gentian Violet. As a result, the exact location and orientation of each piece cut from the membranes relative to both the placental disc and to the region that formerly overlay the cervix was determined. A paper model (tracing) mapping the location and the rupture strength data of each piece is ultimately constructed. This two dimensional map can be folded to show the original three-dimensional physical configuration of the amniotic sac with superimposed Rupture Strength results. This approach confirmed an inherent inhomogeneity in the biomechanics of the gestational sac and clearly demonstrated the para-cervical weak zone. These features had been camouflaged in many previous studies where parts of weak and strong regions were tested together with the assumption of FM homogeneity over its entire surface.

\subsection{Rupture test equipment}

Specialized equipment is necessary to determine FM physical properties. Our testing apparatus, developed in collaboration with Com-Ten industries (a national supplier of 
tensile testing equipment) (Moore et al., 2006), has a number of advantages over that used in previous biomechanical studies of FM: 1. It applies a bi-axial (two dimensional) stretch on the membranes similar to normal physiology; 2 . It uses the puncture mode with any size probe and tissue clamp - it is thus possible to perform a detailed survey of physical properties over the entire fetal membrane surface in a reasonable time period; 3 . It will hold preset displacements or forces for viscoelastic studies; 4 . Probes may be fit with ultrasound sensors for simultaneous measurement of membrane thickness; 5. High precision calibrated accuracy is 0.05 Newton force and $0.01 \mathrm{~cm}$ displacement over appropriate intervals; 6. Tissue specimens are kept moist at all times. 7. Data is captured in digital form, displayed graphically, and analyzed by the software. A force-displacement curve (Fig. 2.) is computer generated during each experiment and the strength characteristics (membrane Rupture Strength, Work to Rupture, Stiffness and other physical properties) are derived and calculated from the data. Data is also exportable for independent analysis.

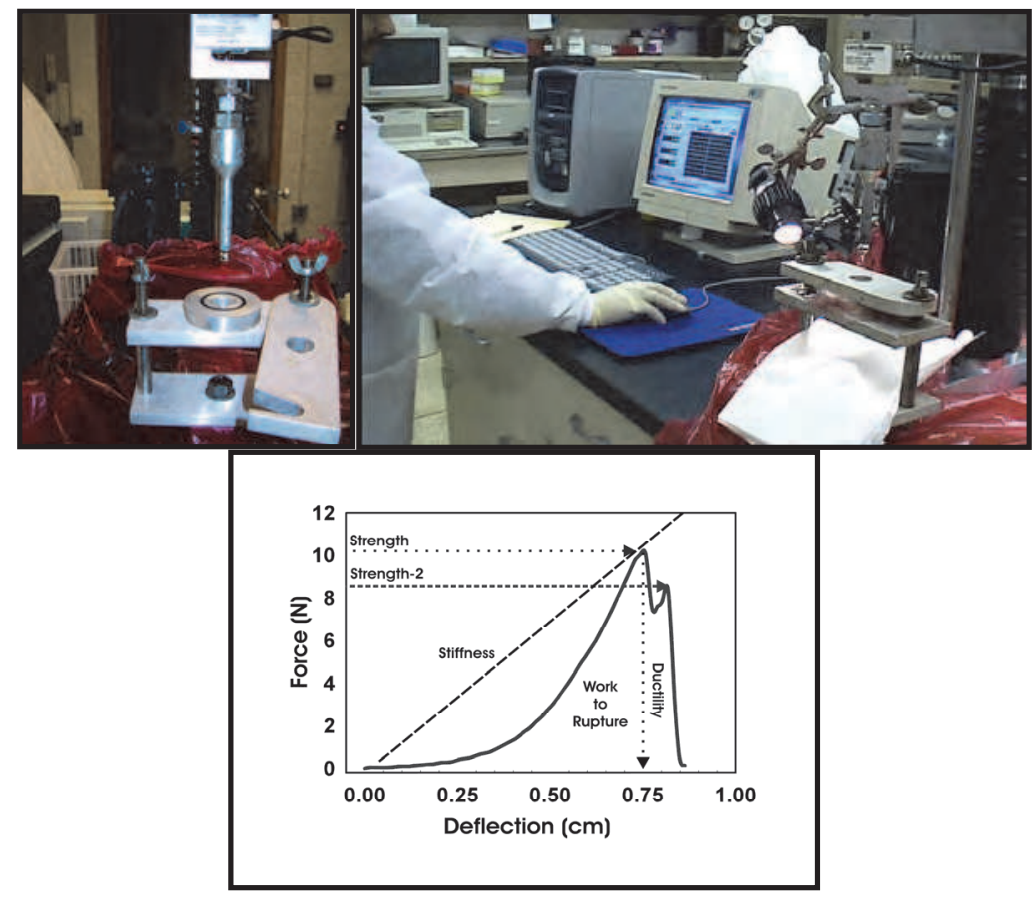

Fig. 2. Strength testing equipment. (Top Left) Close-up view of fetal membrane holding apparatus (from top to bottom - load cell force sensor, rupture probe with spherical tip, membrane holding assembly). (Top Right) Com-Ten Ball-Burst Compression Testing Equipment (from left to right - computer controller, analog-digital converter, membrane rupture assembly). (Bottom) Typical force displacement curve. (Reproduced with permission from El-Khwad et al. Biol Reprod 72:720-726, 2005.)

Development of rupture test equipment and use of this mapping methodology helped us establish the following:

2.2.1. Both term and preterm FM are biomechanically and biochemically heterogeneous over their surfaces. Only by use of this mapping procedure and equipment have we been able to 
identify and topologically map weak areas so that characterization can lead to direct investigation of the mechanism of weakening (El-Khwad et al., 2005, 2006; Rangaswamy et al., 2011).

2.2.2. Sequence of FM rupture - amnion and choriodecidua first stretch together followed by their separation, then choriodecidua ruptures prior to reaching its elastic limit and amnion stretches further in a non-elastic fashion, then ruptures (Arikat et al., 2006).

2.2.3. FM strain hardens with acute cyclical stretch. Like metal pulled into wire it becomes stronger and less elastic. It does not weaken (Pandey et al., 2007).

2.2.4. Determine which physiological agents or processes cause sufficient FM weakening to precipitate rupture, and under what conditions (dose, duration, etc.) this occurs.

\subsection{Equipment to measure adhesion of amnion to choriodecidua}

Discovery that FM (amnion and choriodecidua) separate during the process of rupture led to development of equipment to measure their adherence and allowed us demonstrate that FM peel apart and become less adherent with increasing gestation (Kumar et al., 2009; Strohl et al., 2010). Commercial industrial tensile testing equipment (Com-Ten) was adapted to perform a standard engineering T-peel test to measure the adhesive force of FM (Fig. 3.). Use of this equipment allowed us to determine that FM components become less adherent and separate with increasing gestational age (Strohl et al., 2010).

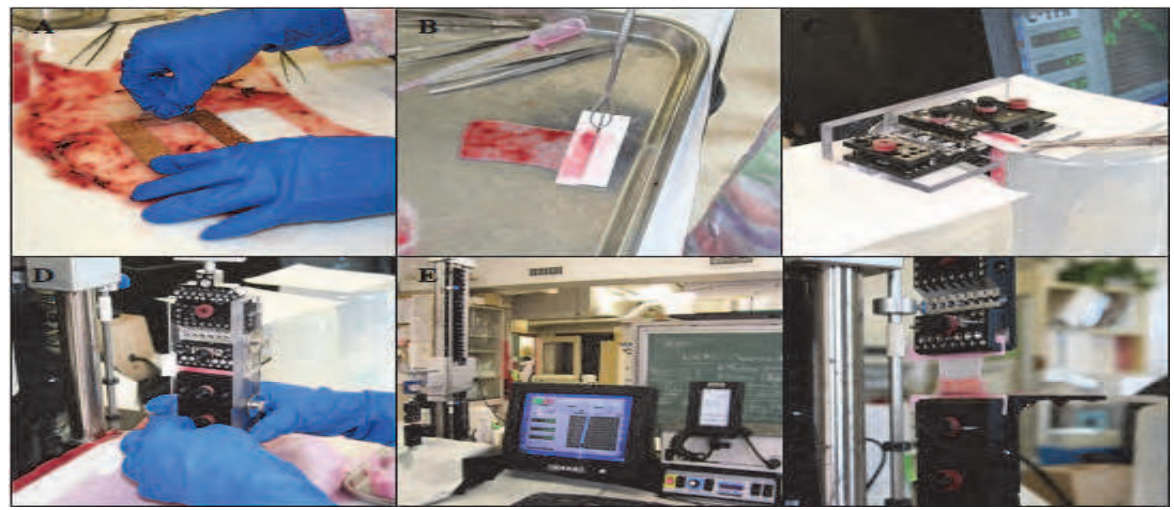

Fig. 3. Peel testing procedures. Tissue samples are cut out from FM kept moist and laid flat and kept moist (A). Stiff filter paper stints assist in holding and mounting the partially manually peeled amnion and choriodecidua by maintaining shape (B). Membrane piece mounted on custom clamps which are maintained in fixed position by a plexiglass mount support to assist sample loading (C). Sample loaded clamps with supporting Plexiglas mount as a single unit attached to the peel testing device (D). The peel tester with the FM piece loaded and the plexiglass mount support removed before beginning the test (E). FM components, amnion and choriodecidua, being peeled apart between the clamp jaws (F).

\section{Para-cervical weak zone in FM - A result of programmed biochemical weakening processes}

Rupture of FM (ROM) is an integral event in the onset and development of labor. Even though ROM usually follows uterine contractions, it precedes the onset of contractions in at 
least $10 \%$ of term labor and $40 \%$ of premature labor. This implies that the stretch force alone is not the cause of FM weakening.

\subsection{Term FM develops a para-cervical "weak zone" where rupture initiates}

Rat model studies suggest that amnion, the strongest component of FM undergoes collagen remodelling as gestation progresses (Paavola et al., 1995; Lockwood et al., 1999). As a result of these phenomena, FM is postulated to weaken and become more susceptible to rupture near the end of gestation. Apoptosis has also been suggested to occur near term in human amnion and chorion (McLaren et al., 2000a). Malak and Bell first identified an area of socalled "high morphological change" in the zone of FM overlying the cervix (Malak \& Bell, 1994). This distinct para-cervical region has been demonstrated in the FM from both term vaginal and caesarean section deliveries without labor and comprises approximately $2-10 \%$ of the total FM surface area (McLaren et al., 1999a; McParland et al., 2003). Bell's group further characterized this area of FM as having increased matrix metalloproteinase (MMP) -9, increased trophoblast apoptosis, differences in the thickness of membrane sub layers, and increased myofibroblasts in this area (McLaren et al., 1999b, 2000a, 2000b; McParland et al., 2003). Lappas and colleagues have confirmed an increase in apoptotic markers, and have reported increased NF-kB activity and acetylated-forkhead box O1 protein expression in the para-cervical FM region (Reti et al., 2007; Lappas et al., 2009). All these studies have presumed that remodelling in this para-cervical zone leads to FM weakening and subsequent rupture.

We have identified a focal "weak zone" with biochemical characteristics equivalent to the previously described "zone of high morphological change" in the para-cervical region of FM. Using FM from repeat cesarean section performed prior to any labor, we showed that this region ruptures with only $20-50 \%$ of the force required to rupture other areas of the FM (Fig. 4.), and that it exhibits a biochemical signature of increased collagen remodeling and apoptosis (El-Khwad et al., 2005). Western Blot analysis indicated increases in matrix metalloproteinase 9 (MMP-9) and cleaved PARP, and decreases in fibulins 1, 3, 5 and TIMP3 in the Weak Zone. MMP-2 did not show differences. TIMP-1 was barely detectable; TIMP2 and TIMP-4 protein were detectable in all specimens but did not change with Strength. Other groups have also confirmed the increase in markers of collagen remodeling and apoptosis (Malak \& Bell et al., 1994; El-Khwad et al., 2005, 2006; Meinert et al., 2007, Reti et al., 2007; Han et al., 2008; Lappas et al, 2008, 2009, 2010a, 2010b).

Using FM from patients with AROM (artificial rupture of membranes) and SROM (spontaneous rupture of membranes), we have further demonstrated that the para-cervical weak zone persists with the same biochemical signature as that identified in pre-labor cesarean section membranes. As the rupture tear line usually extends through the weak zone, we have postulated that it contains the site of initiation of FM rupture (El-Khwad et al., 2005, 2006). We have also demonstrated that acute, repetitive stretch does not weaken, but paradoxically strengthens FM (Pandey V et al., 2007). Our studies, those of the Bell group, and now those of four other groups (as indicated above) thus strongly support the concept of regional differences in FM properties, most specifically, that the area over the cervix is significantly weaker than the rest of the FM with concomitant differences in biochemical and histological properties. Taken together, the data indicate that term FM normally weakens in late gestation as a result of programmed biochemically mediated processes. Presumably, spontaneous FM rupture at term usually results from the mechanical stresses of labor upon biochemically pre-weakened membranes. 


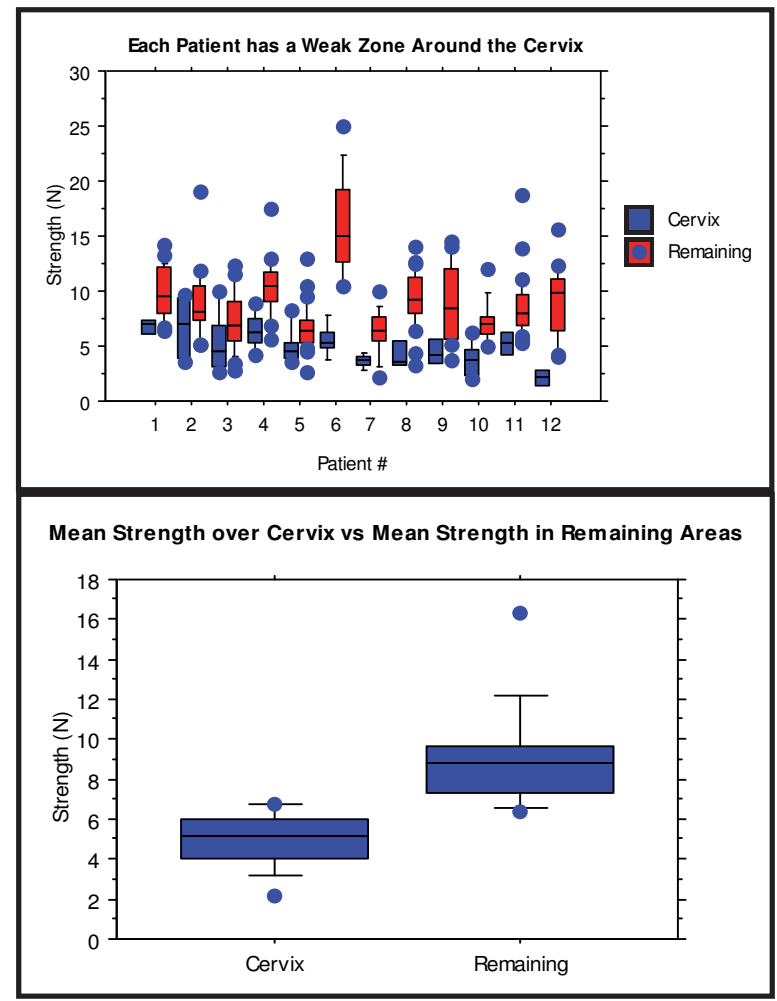

Fig. 4. Fetal membrane strength. [Bottom] Mean strength of cervical zones for each patient is less than the mean strength of the remaining areas $(\mathrm{P}<0.001)$. [Top] Individual patient data showing a weaker cervical zone for each of the 12 patients relative to the remaining areas. (Reproduced with permission from El-Khwad et al. Biol Reprod 72:720-726, 2005.)

\subsection{Role of MMP activation and apoptosis in the weak zone formation}

Fortunato and Menon (2004) have extensively reviewed the roles played by MMPs and apoptosis in FM rupture. The strength of amnion and chorion is largely due to collagen. Collagens I, III, IV, V and VI have been described in various layers of amniochorion. The major strength in amnion is derived from collagen I (seen extensively in the compact layer and adjacent mesoderm) and collagen IV (a major component of the basement membrane and of the bundles connecting the mesenchymal layer and the epithelium) (Bachmaier et al., 1999). Degradation of collagen is controlled by specific MMPs as modulated by tissue inhibitors of matrix metalloproteinases (TIMPs). Thus, the ratio of MMPs and TIMPs is a good indicator of collagen degradation, which along with the deposition rate of new collagen by fibroblasts, determines the ultimate tissue strength. Although MMP types 1, 2, 3, 8 and 9 have been well described in amniochorion; major investigative work in FM has been done with MMP types 2 and 9. MMP-1 predominates prior to the onset of contractions as described by Bryant-Greenwood and Yamamoto. FM MMP-2 is constitutive and reportedly does not respond to cytokines or change with PPROM or labor (term or preterm) [Fortunato et al., 1999; Maymon et al., 2001; Xu et al., 2002]. In contrast, both active and latent forms of 
MMP-9 have been shown to increase in human amniotic fluid with PPROM and in amniotic fluid of rhesus monkeys after inducing labor with cytokines (Bryant-Greenwood et al., 1995; Osmers et al., 1995; Athayde et al., 1999; Vadillo-Ortega et al., 2002). MMP-9 can also be induced in FM tissue with $\mathrm{PGE}_{2}, \mathrm{PGF}_{2 \alpha}, \mathrm{TNF}_{\alpha}$ and ROS (Buhimschi et al., 2000; Sciscione et al., 2001; Ulug et al., 2001; Arechavaleta-Velasco et al., 2002; Zaga et al., 2004). TIMP-1, which controls the activity of MMP-9, has been extensively studied in FM and found to decrease with PROM and labor (Ulug et al., 2001; Arechavaleta-Velasco et al., 2002; Buhimschi et al., 2000; Zaga et al., 2004; McLaren et al., 2000b). Thus we conclude that MMP9 plays a major role in FM remodeling, weakening and rupture. Our work also demonstrates that MMP-9 levels are an excellent marker for FM strength (El-Khwad et al., 2005, 2006; Kumar et al., 2006; R.M. Moore et al., 2009b) [Fig. 5, 7, 8, 10]. TIMP-3 has a direct correlation with FM rupture strength (unlike TIMP types 1 and 2) and was significantly decreased in the weak zone (El-Khwad et al., 2005, 2006). Unlike other TIMPs, TIMP-3 inhibits all the gelatinases, TNF-a, and also is stored within ECM (Mannello et al., 2001).

MMP activation and apoptosis are often interrelated. The ECM acts a major stabilizing factor in many tissue systems. This stability is compromised when MMP activation leads to the breakdown of ECM leading to apoptosis (Boudreau et al., 1995; Chintala e al., 2002). MMPs may also induce apoptosis by cleaving membrane bound cytokines, including TNFa and FasL (Gearing et al., 1994; Kayagaki et al., 1995). Apoptosis can also induce activation of MMPs. In addition, the same agents which have been reported to cause apoptosis in FM tissue also activate and increase transcription of MMPs, specifically, MMP-1, MMP-9 (So et al., 1992; Fortunato et al., 2002). We have reported a parallel increase in prostaglandins with induction of apoptosis in amnion epithelial, mesenchymal and WISH cells with several non-physiological (actinomycin D, cycloheximide, staurosporin) and physiological (ceramide, lactosylceramide, PGJ2 metabolites) apoptotic agents (Moore et al., 1988, 1993).

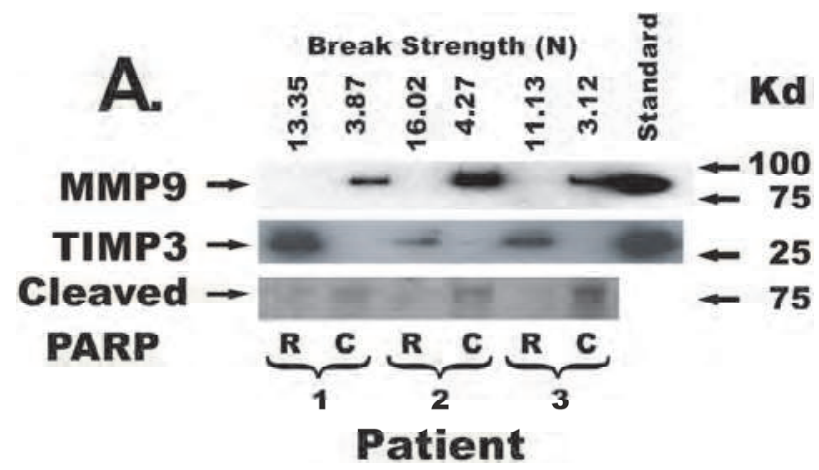

Fig. 5. Biochemical characteristics of fetal membrane regions: Western blot showing differences in MMP-9, TIMP-3 and PARP cleavage between weak, paracervical regions (C) and relatively strong remaining areas $(\mathrm{R})$. Typical Western blot showing parallel strength differences in cervical $(\mathrm{C})$ and remaining $(\mathrm{R})$ areas of the fetal membranes from three patients. (Reproduced with permission from El-Khwad et al. Biol Reprod 72:720-726, 2005.)

Prostaglandins also induce transcription and activate MMPs in most tissues (Lyons et al., 2002; Yoshida et al., 2002). The apoptotic process, thus, potentially weakens FM by eliminating fibroblastic cells, which lay down new collagen, and simultaneously activates 
enzyme systems, which break down existing collagen. Activation of MMPs feeds forward to increase apoptosis, which subsequently feeds back to further increase MMP activation.

The physiological mechanisms that initiate MMP activation and apoptosis in FM are not understood. Many constituents of amniotic fluid whose concentrations increase with gestation, with infection, or even with rupture of membranes (TNFa, IL-1 $\beta$, lactosylceramide, etc) have been shown to cause apoptosis in cells derived from FM and intact membranes (Moore et al., 1988, 1993). Most of these "apoptotic" agents also increase transcription or activation of MMPs, especially MMP-9 (Kumar et al., 2006; R.M. Moore et al., 2009b; Menon et al., 2004; Zaga et al., 2004). Several groups have proposed the synergistic effects of MMP activation and apoptosis leading to rupture of the FM (McLaren et al., 2000a; Fortunato et al., 2000; Bowen et al., 2002; Lei et al., 1996). The promoter polymorphisms in some cytokines (TNFa and IL-1 $\beta$ ) and MMPs $(-1,-8,-9)$ have been identified to be associated with PPROM (Ferrand et al., 2002; Fujimoto et al., 2002; Hernandez-Guerrero et al., 2003; Roberts et al., 1999). Patients with these polymorphisms may have earlier initiation of the programmed weakening process resulting in premature rupture of FM and earlier deliveries.

\subsection{Structural protein changes in the extracellular matrix of the "weak zone" in FM}

As part of the remodeling processes in the weak zone, there must be changes in the structural proteins that could contribute to the weakening of FM. Changes in MMPs and TIMPs on their own do not result in weakening and rupture of FM. The collagen structural units or other components of extracellular matrix (ECM) may undergo degradation resulting in weakening of FM. At least half of the published reports found no decrease in fibrillar collagen in the area of the rupture site in human FM, however (Manabe et al., 1991; Al-Zaid et al., 1980; Evaldson et al., 1987; Halaburt et al., 1989). This is in contrast to animal studies in which collagen degradation is the major factor in remodeling of FM (Lei et al., 1996). There is some evidence that other processes play a crucial role in human FM weakening: 1 . Collagen fiber bundles are more dispersed and less well organized in the area of FM rupture site as demonstrated through X-ray diffraction and microscopy (Connon et al., 2007). This disorganization is also supported by evidence that decorin and biglycan are decreased and increased respectively at the site of FM rupture (Meinert et al., 2001 \& 2007). Decorin is a protein that promotes protein fiber organization and biglycan has the opposite effect. 2. FM mesenchymal cells undergo "phenotypic switching" from strength promoting myofibroblasts to macrophages that are capable of producing cytokines which weaken the FM (Kim et al., 2008). 3. Numerous studies have demonstrated increased apoptotic activity near the site of SROM (Runic et al., 1998; Yuan et al., 2009; Sagol et al., 2002). 4. We have reported that three members of the fibulin protein family are decreased in the para-cervical weak zone (R.M. Moore et al., 2009a). These proteins are involved in making bridges in the microfibrillar component of the ECM, thus this protein family is clearly of potential interest in the remodeling process that weakens FM prior to rupture. There have been no previous reports describing fibulin family proteins in amnion. We also demonstrated that amnion epithelial and mesenchymal cells produced all three fibulins and their abundance was inhibited by TNF- $\alpha$, a cytokine involved in weakening of FM (Ossovskaya et al., 2004). We speculate that the amnion microfibrillar layer undergoes significant remodeling with the development of FM weak zone. 


\subsection{Stretch forces increase rupture strength of the FM rather than decreasing it}

It was previously thought that during labor, the FM weakens progressively as a result of repetitive stretching due to contractions. Toppozada (Toppozada et al., 1970) showed that the specific contraction causing rupture of membranes was rarely the most forceful contraction that had been experienced up to that time. They reasoned that prior contractions weakened the membrane so that it subsequently gave way with less force. Lavery described stress relaxation, creep and thinning in FM as part of their study of viscoelastic properties (Lavery et al., 1977, 1982). They assumed, but did not demonstrate, that membranes were weaker (had a lower Rupture Strength) after experiencing viscoelastic, non-recoverable deformation. To test this hypothesis, we collected term vaginally delivered, FM, which were strength tested after being cyclically stretched (Pandey et al., 2007). Rupture Strength and Work to rupture were determined for intact unstretched FM (control) and compared with topographically adjacent FM pieces which were stretched to $75 \%$ of the Rupture Strength of controls, for 5, 10 or more cycles of 10 seconds each. Repeated stretching caused non-elastic deformation of the FM as reported by Lavery et al but the Rupture Strength after repeated stretching paradoxically increased rather than decreased. Stretched FM Rupture Strength increased $20-40 \%$ with respect to controls after 5 or 10 cycles. In contrast, Work to Rupture decreased. After a large number of cycles (20-30), Rupture Strength ultimately decreased. The number of cycles of stretch required to promote weakening of the FM was highly variable and may be related to the cycles that the membrane had gone through prior to delivery. When separated FM components were tested, amnion alone showed the same altered pattern of Rupture Strength and Work to Rupture after stretch cycling as the intact tissue - Rupture Strength initially increased while Work to Rupture decreased. Choriodecidua did not exhibit properties of stretch induced deformation. FM thus undergo deformation with stretch cycling. The initial cycles of high force stretching causes an increase in FM Rupture Strength, but decreased Work to Rupture (likely due to the amnion component alone). With continued cycling, Rupture Strength also ultimately decreased. We speculate that collagen fibers in FM may realign during initial stretch cycles as they do in stretched skin and cartilage. This may effectively strain harden the FM, increasing Rupture Strength and thus protecting the FM from precipitous rupture. This protective mechanism may fail after many cycles of stretch allowing FM to rupture at lower Rupture Strength and lower Work to Rupture.

\section{Preterm Premature Rupture of FM}

The precipitant causes of preterm FM weakening leading to PPROM remain uncertain. Limited data is available on FM physical properties in preterm patients. The studies in our laboratory utilizing our methodology confirm that premature FM are stronger than term with a significant drop-off after 37 to 38 weeks gestation (Rangaswamy et al., 2011; fig. 6.). Other researchers (Pressman et al., 2002; Lavery et al., 1979; Chua et al., 2009) have studied the effects of gestational age on FM strength and noted a statistically significant decrease in FM tensile strength after 39 weeks gestation which is consistent with our findings. Our study is the first to demonstrate heterogeneity in biomechanical properties across preterm FM as we have previously shown in term FM (El-Khwad et al., 2005). This mandates that a greater degree of remodeling and/or degradation would be necessary for preterm FM to rupture than occurs in term FM. Although a definitive para-cervical Weak Zone cannot usually be located in PPROM FM because the para-cervical region cannot be marked prior to delivery, a relative weak zone along the rupture tear line is generally present. 


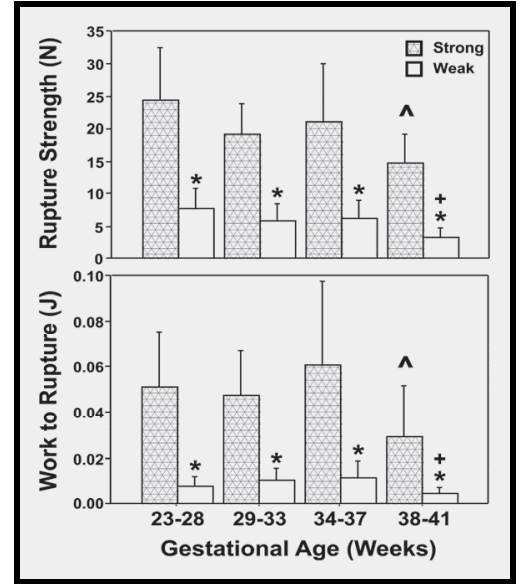

Fig. 6. FM rupture strength (upper panel) and work to rupture (lower panel) comparing the weak zone vs. strong areas across gestational groups: A decreasing trend in both rupture strength and work to rupture is shown from preterm to term gestation (Data are presented as the mean $\pm \mathrm{SD},{ }^{\wedge}{ }^{*}$ indicate $\left.\mathrm{p}<0.001\right)$. Reproduced with permission from Gynecol Obstet Fertil. 2011 ; 39(6):373-377 (Rangaswamy et.al., 2011).

Although the mechanism of FM rupture at term or with PPROM is not well understood, we believe that PPROM occurs due to an abnormal early activation of the processes that weaken FM at term. Supportive findings of this theory are the marked upregulation of MMPs, pro-inflammatory cytokines and chemokines in amniotic fluid and FM in PPROM and chorioamnionitis (Cox et al., 1997; Maymon et al., 1999; Thomakos et al., 2010; BryantGreenwood et al., 1995; Fortunato et al., 2003; Riley et al., 1999; Locksmith et al., 2001; Xu et al., 2002). TNF and IL-1 $\beta$ specifically have been shown to induce apoptosis, induce MMP 9 and increase $\mathrm{PGE}_{2}$ production in chorioamnion and cultured primary amnion cells (R.M. Moore et al., 2009b; Runic et al., 1998; Fortunato et al., 2001; Furuta et al., 2000; LundinSchiller et al., 1991; Garcia-Lloret et al., 1996; Lockwood et al., 2008). We previously reported that several physiological agents and reactive oxygen species (hydrogen peroxide) induce apoptosis with concomitant $\mathrm{PGE}_{2}$ release in amnion derived WISH cells, primary amnion cells and intact amnion (Kumar et al., 2004 a, 2004 b).

Inflammation due to an ascending bacterial infection from the female genital tract remains the most widely speculated cause as up to 55 percent of patients with PPROM had culture or PCR evidence of infection (Jones et al., 2009). Inflammatory processes at sites remote from the female genital tract (e.g.: periodontal infections) may also increase the levels of proinflammatory cytokines at the materno-fetal, interface (Offenbacher et al., 2006; Carta et al., 2004). Decidual hemorrhage/abruption is also highly associated with PPROM (Harger et al., 1990; Salafia et al., 1995). Additional risk factors include advanced maternal age, primiparity, (Ladfors et al., 2000) smoking, (Burguet et al., 2004) short cervical length (Iams et al., 1996) structural abnormality of chorioamniotic membranes (Stuart et al., 2005), and PPROM with preterm birth in a previous pregnancy (Ladfors et al., 2000; Lee et al., 2003; Shen et al., 2008). African American women are at higher risk of PPROM than Caucasian women (Goldenberg et al., 1996a), which might be due to racial differences in the regulation of promoter activity of pro-inflammatory cytokines and MMPs (Simhan et al., 2003; Ferrand et al., 2002). 
Two major processes that have been associated with PPROM are inflammation (due to infection and other etiologies) and decidual hemorrhage/abruption. We have developed and utilized a unique model system to investigate FM weakening due to each of these etiologies and identified a pharmacological agent with potential role in preventing this weakening process, which will be discussed in the next two sections.

\section{Investigations to understand mechanism(s) of FM weakening and rupture}

\subsection{Development of an in vitro model system to study the mechanisms of FM rupture}

There are no animal models for the study of human FM weakening and rupture. We have used FM strength testing equipment and methods that allow us to systematically measure and map human FM biomechanical properties over the entire FM surface and correlate these with local biochemical properties (as discussed above) in conjunction with an adaptation of the explant culture system developed by Fortunato and Menon (Fortunato et al., 1994) to produce a model system to study the process of human FM weakening (R.M. Moore et al., 2006, 2009b, 2010; Kumar et al., 2011; Mercer et al., 2010). Full thickness FM explants are cut from regions of the FM distant from the Weak Zone of FM from unlabored Cesarean deliveries. The explants are then incubated for 2 to 4 days with agents postulated to affect the weakening process. Biomechanical testing is then performed and correlated with local induced biochemical changes in the immediately adjacent tissue. This model system is novel and unique in its ability to quantitatively measure FM weakening, the major parameter of clinical interest, as well as the associated biochemical changes. We are using this model system to explore the mechanisms by which FM weakening occurs as the result of two processes, inflammation/infection and decidual hemorrhage/abruption, which are both highly associated with preterm birth due to PPROM.

\subsection{Inflammation/Infection induced FM weakening}

Under normal circumstances, pregnancy is regulated by a balanced activity of antiinflammatory and pro-inflammatory cytokines/chemokines (Ugwumadu et al., 2002; Diehl et al., 2002). They play an important role in placental growth and development (Croy et al., 2002). Progesterone may play an important role in continuation of pregnancy by promoting anti-inflammatory cytokines over pro-inflammatory cytokines. During the end of pregnancy at term, the activity of pro-inflammatory cytokines dominates resulting in the weakening and rupture of FM. At term, the amniotic fluid contains anti-inflammatory cytokines IL-10, IL-4, IL-1 receptor antagonist (Il-1RA) and transforming growth factor $-\beta$ (TGF- $\beta$ ) [Jones et al., 1997; Dudley et al., 1996; Baergen et al., 1994; Romero et al., 1992b; A.G. Moore et al., 2000; Heikkinen et al., 2001]. The functions of these cytokines include suppressing proinflammatory cytokines (by IL-4), modulation of IL-1 mediated inflammatory effects (by IL1RA) and inhibition of production of pro-inflammatory cytokines and suppression of the activity of antigen presenting cells (by IL-10).

The role of cytokines is not just limited to normal childbirth but also occurs in births (including preterm births) associated with infection. However, there are likely some differences (Bryant-Greenwood et al., 2007; Osman et al., 2006; Haddad et al., 2006; Beutler et al., 2004). The severity of inflammatory response that occurs in normal labor is relatively less compared to that seen in infections (Rusterholz et al., 2007). Relaxins, nuclear factor (NF)-kB and toll-like receptor (TLR)-2 are all part of the inflammatory cascade that result in 
term/preterm labor or weakening and rupture of FM (Bryant-Greenwood et al., 2009; Millar et al., 1998; Werner et al., 2005; Hoebe et al., 2004). The amniotic fluid in normal uncomplicated pregnancy shows elevated pro-inflammatory cytokines (IL-1 $\beta$, IL-6 and TNF- $\alpha$ ) with increasing gestation (Opsjln et al., 1993; Romero et al., 1990b; Laham et al., 1994 \& 1996), which is further increased during labor at term (Opsjln et al., 1993; Romero et al., 1990b; Laham et al., 1994; Cox et al., 1997; Maymon et al., 1999; Gunn et al., 1996; Romero et al., 1990a \& 1992a). Infection during pregnancy further elevates the levels of these cytokines in amniotic fluid, FM and decidua (Goldenberg et al., 2000). This fact holds well even in preterm deliveries (compared to term) especially with infection and PPROM (Cox et al., 1997; Maymon et al., 1999; Romero et al., 1988 \& 1993). The source of these cytokines is the infiltrating leucocytes as demonstrated by immunolocalization studies of gestational tissues (Young et al., 2002). Both amniotic fluid IL-16 and IL-18 are increased with infection. IL-18 is a pleiotropic cytokine that plays a role in host defense against infection whereas IL-16 is unique, functioning as a chemoattractant, modulator of lymphocytes, monocytes, eosinophils and dendritic cells, and in cell cycle control (Jones et al., 2009). On the other hand, the anti-inflammatory cytokines also increase with term and preterm labor, the most marked elevation occurring in preterm delivery with infection.

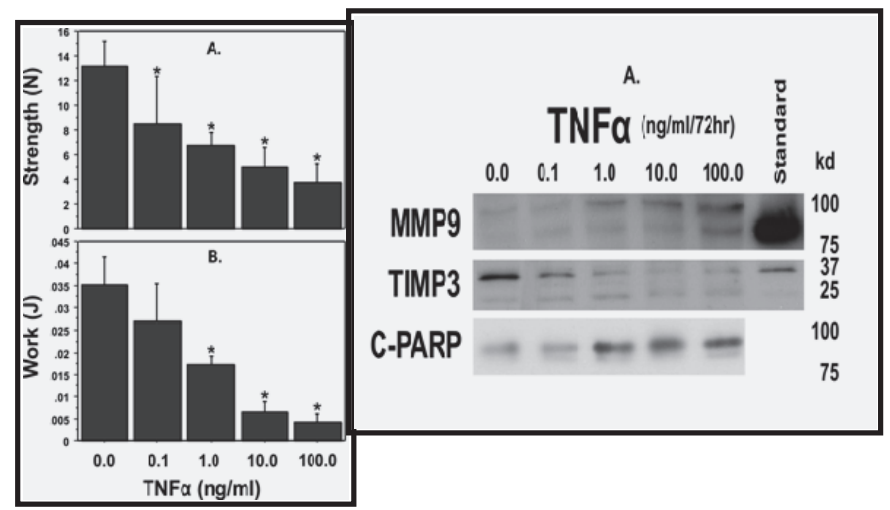

Fig. 7. TNF weakens full thickness FM. [Left] TNF-induced dose-dependent decreases in FM strength (A) and work to rupture (B). Incubations were for $72 \mathrm{~h}$. [Right] TNF (0-100 ng/ml for $72 \mathrm{~h}$ ) induced increases in MMP9 protein (upper panel) and decreased TIMP3 protein (middle panel) in FM explants in a dose-dependent manner. TNF also induced apoptosis in FM explants as evidenced by cleavage of PARP1 (113 kD) into $85 \mathrm{kD}$ fragments (lower panel). Reproduced with permission from Biol Reprod 74:29-34, 2006 (Kumar D et al., 2006).

The tissue and cellular pathways involved in cytokine induced FM weakening are not fully understood. Although it has been generally assumed that collagen remodeling and apoptosis lead to FM weakening and rupture, this had not been directly demonstrated prior to our recent studies. Using our in vitro model system we have shown that inflammatory cytokines (TNF and IL-1 $\beta$ ) weaken full thickness FM explants in a dose dependent manner concomitant with biochemical changes that mimic the signature of the natural Weak Zone (Fig. 7.) Cytokines act on FM in a complex manner. As the amnion is the strongest component of the FM, it must be significantly weakened in any mechanistic schema leading 
to rupture (Arikat et al., 2006). Our published data show that cytokines do not weaken the isolated amnion, but readily weaken amnion when it is adherent to the choriodecidua as part of the full thickness FM (Kumar et al., 2011) [Fig. 8.]. In contrast, conditioned media produced by incubating isolated choriodecidua with cytokines readily weaken the amnion. It is thus clear that a critical cytokine target for FM weakening is in the choriodecidua, where one or more soluble products are produced which are necessary for TNF or IL-1 $\beta$ induced weakening of the amnion.
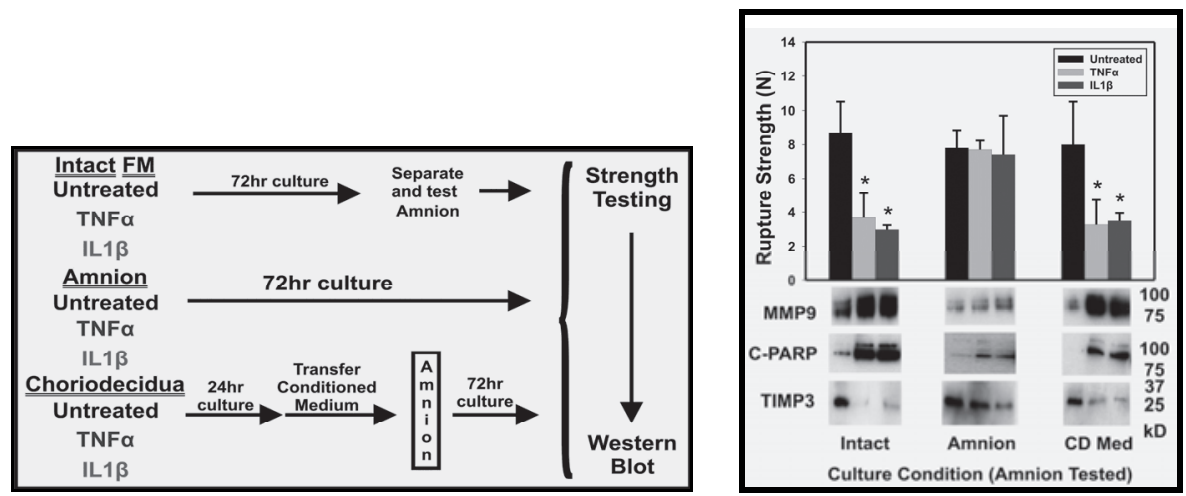

Fig. 8. TNF and IL-1 $\beta$ cannot weaken isolated amnion directly: Experiment description [left] and results [right]. Isolated amnion when incubated with cytokines (center group of results) showed no decrease in strength and minimal changes in MMP9, TIMP3 and cleaved PARP. Amnion exposed to conditioned media from choriodecidua incubated with cytokines showed weakening and biochemical changes (right group of results). Control study results show amnion weakening with intact FM stimulation (left group of results). Reproduced with permission from Placenta 32(3):206-213, 2011 (Kumar D et al., 2011).

\subsection{Decidual hemorrhage/abruption induced FM weakening}

Thrombin may be produced in FM by decidual hemorrhage/abruption and activation of the extrinsic coagulation cascade. Decidual cells have been shown to have abundant tissue factor thus facilitating the production of Thrombin after hemorrhage (Lockwood et al., 1993 $\&$ 2001). PPROM patients have increased tissue factor (Erez et al., 2008). Thrombin is known to have many actions not related to coagulation. Thrombin can act directly on the extracellular matrix (ECM) by converting MMPs 1, 2, 3 and 9 from zymogen to active forms (Fang et al., 2006; Lafleur et al., 2001). Alternatively, it can act indirectly, through cells, by activating Protease Activated Receptors (PAR) (Hollenberg et al., 2005; Ossovskaya et al., 2004) and thereby inducing MMPs and other proteins, which may remodel the ECM. Thrombin has been shown to induce MMP9 in monocytes (Chi-Jen Chang et al., 2009), oral squamous cell carcinoma (Liu et al., 2001), human dermal fibroblast (Wang et al., 2007) and mesangial cells (Liu et al., 2000), microvascular endothelial cells from human brain (Kolev et al., 2003) and rabbit aortic smooth muscle cells (Fabunmi et al., 1996). Four PARs (1 - 4) have been described but none have yet been reported in FM. PARs are activated by the proteolytic activity of thrombin and other serine proteases (thrombin acts on PARs 1, 3 and 4 and trypsin acts upon PAR 2). These enzymes cleave the N-terminus of the receptor, 
which thereafter permanently acts as a tethered ligand causing a physiological response. Synthetic PAR activating peptides (PAR-AP) composed of the initial amino acid string of the new N-terminus generated when thrombin cleaves PAR, can activate their specific PAR independent of thrombin or receptor cleavage (Refer table below).

\begin{tabular}{|l|l|l|}
\hline Receptor & Activating Peptide & Control Peptide \\
\hline PAR 1 & TFLLR-NH2 & FTLLR-NH2 \\
\hline PAR 2 & SLIGRL-NH2; 2furoyl-LIGRLO-NH2 & LSIGRL-NH2; 2furoyl-OLRGIL-NH2 \\
\hline PAR 3 & NOT activated by PAR-APs & -------- \\
\hline PAR 4 & AYPGKF-NH2 & YAPGKF-NH2 \\
\hline
\end{tabular}

Table 1.

These PAR-APs have been used extensively as pharmacological tools for probing the effects of specific PAR activation in cells and tissues independent of the other effects of thrombin. PAR-APs are commercially available for most of the PAR receptors (table). Inactive control peptides with a reversal of two AA's are also available (Ramachandran \& Hollenberg, 2008). We have evidence that the PAR-AP for PAR 1 weakens isolated amnion (fig 10 - sub figure 2). The PAR receptors act through G-proteins families including: I (cAMP inhibitory), 12/13 (Raf/Ras activation) or $\mathrm{q}$ (calcium signaling) which in turn activate a number of signaling cascades including MAP kinases, Akt/PKB, P13 kinase and NFkB (101).

Our recent report demonstrates that Thrombin weakens full thickness FM in a dose dependent fashion in our model system (Moore et al., 2010, fig. 9). We have also reported that Thrombin increases both the zymogen and active forms of MMP-9 and MMP-3 in the amnion (Furuta et al., 2000). The latter is particularly interesting as MMP-3 can activate other MMPs, especially MMP-2, which is prevalent in the amnion but is not further induced by either cytokines or Thrombin.
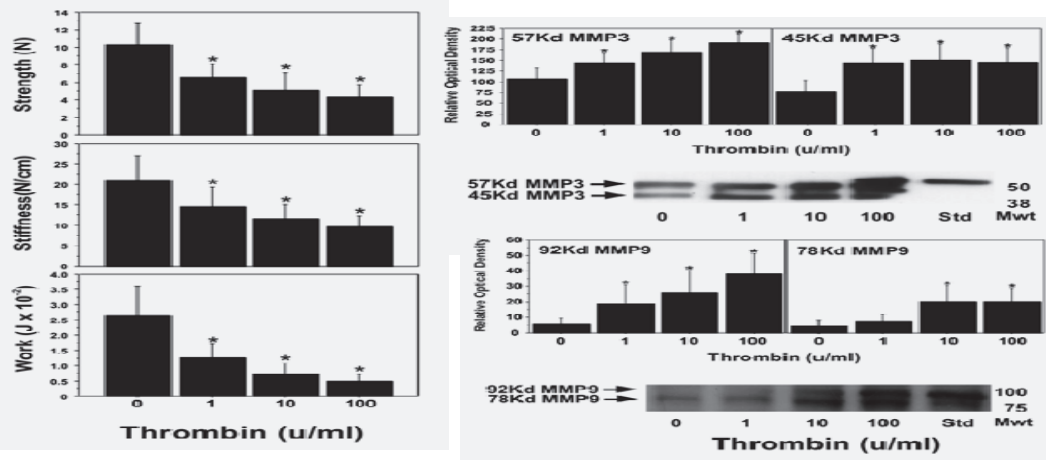

Fig. 9. Thrombin weakens full thickness FM. [Left] Thrombin-induced dose-dependent decreases in FM strength, stiffness and work to rupture. All incubations were for $48 \mathrm{~h}$. $\left({ }^{*} \mathrm{P}<0.01\right)$. [Right] Thrombin induced increases in MMP3 protein (upper panel) and MMP9 protein (lower panel) in FM explants in a dose-dependent manner. (Reproduced with permission from Moore et al. Placenta 2010.) 
In further work we have found that, unlike cytokines, thrombin can directly weaken the isolated amnion. The critical targets for thrombin are thus in amnion rather than the choriodecidua. [Fig. 10 - subfigures 1, 3 \& 4]
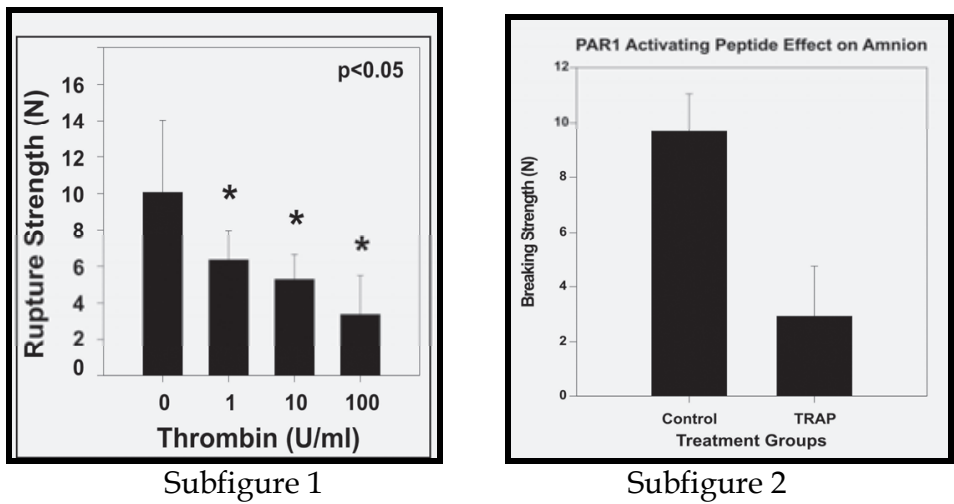

Subfigure 2

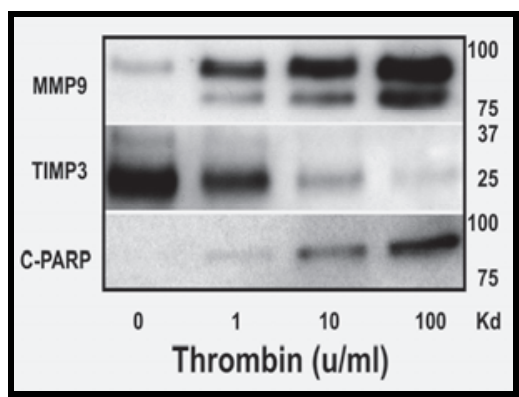

Subfigure 3

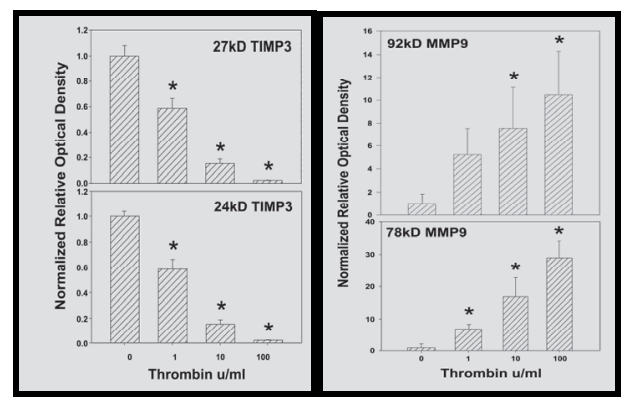

Subfigure 4

Fig. 10. [Top Left] Thrombin weakens isolated amnion. ( ${ }^{*} p<.01$ vs. control), [Top Right] PAR 1 ( $1 \mathrm{uM})$ activating peptide (TRAP) weakens isolated amnion $(\mathrm{p}<.001)$, [Below] Thrombin increases MMP9, decreases TIMP3 and increases PARP cleavage in isolated amnion (all * $\mathrm{p}<.001)$. (Reproduced with permission from Kumar et al. Placenta 2011.)

\subsection{Inflammatory cytokines and thrombin have different mechanisms of FM weakening}

As the amnion is the strongest component of the FM, it must be significantly weakened in any mechanistic schema leading to rupture. For this reason agents that weaken FM were tested for their effect upon isolated amnion membranes. Cytokines (TNF or IL-1 $\beta$ ) do not weaken the isolated amnion, but readily weaken amnion when it is adherent to the choriodecidua as part of the full thickness FM. In contrast, conditioned media produced by incubating isolated choriodecidua with these cytokines readily weaken the amnion. It is thus clear that a critical cytokine target for FM weakening is in the choriodecidua, where one or more soluble products are produced which are necessary for TNF or IL-1 $\beta$ induced weakening of the amnion (Kumar et al., 2011). On the other hand Thrombin can directly 
weaken the isolated amnion. The critical targets for Thrombin induced FM weakening are thus in amnion rather than the choriodecidua (Kumar et al., 2011).

\section{Investigations targeting the potential prevention of FM weakening and rupture}

\subsection{Tissue repair and prevention of weakness}

A major objective of research into the physiology of FM rupture is the development of possible strategies for membrane repair or prevention of premature weakening. Studies of tissue repair after physically induced injury have been limited. Artal (Artal et al., 1976) demonstrated that membranes placed in pseudo-amniotic fluid become weaker over 24 hours but remain unchanged if a mixture of pharmacological enzyme inhibitors is included. The tissue surrounding a stab wound in FM has been shown to be viable for up to 12 days but the wound remained unhealed (Devlieger et al., 2000a). Millar et al (2003) demonstrated increased growth of amnion epithelium with IGF-II. Using a rabbit model, Devlieger et al (2000b \& 2003) have shown some success in incorporating plugs into iatrogenic ruptured sites. Growth factors, TGF $\beta$ and FGF $\beta$, which normally accelerate repair in other tissues, were shown by the same group to improve the rate of FM repair, although the concomitant increased inflammatory response was of concern because of its possible exacerbation of events leading to premature delivery (Devlieger et al., 2003). FM injured in vitro, thus seem to have minimal tendency for self-repair. Clinical studies of FM sealants and sealing techniques have been undertaken in hopes of restoring amniotic fluid volume and averting the risks of prolonged oligohydramnios after extremely early PPROM. An in vitro study has revealed that platelets aggregate with exposure to amnion, but not to chorion or amniotic fluid, and that platelet adhesion and activation occur with exposure to the connective tissues underlying amnion and chorion but not amniotic epithelium (Louis-Sylvestre et al., 1998). Similarly, Harmali et al have demonstrated improved membrane tensile strength (Rupture Tension, Strain to Rupture, and Work to Rupture) with iatrogenic defects after application of a fibrin sealant, but that the membrane strength remains less than that of unruptured membrane segments (Harmanli et al., 1998). Fibrin/thrombin based sealants, but not platelet infusions, have been shown to cause temporary cessation of leakage (Reddy et al., 2001). Regarding non-biologic barriers, O'Brien et al (2001) evaluated gelatin sponge (Gelfoam, TM) applied over larger defects and found it to effectively dam linear defects of up to $7 \mathrm{~mm}$ in length, but not complex defects. The ability to fuse ("weld") FM with Nd: YAG Laser applied to polytetrafluoroethylene has also been demonstrated in-vitro, though the ability of such intervention to seal a membrane defect has not (Mendoza et al., 1999).

There has been some success in the treatment of iatrogenic membrane rupture. In 1999, Quintero and co-workers (Quintero et al., 1998 \& 1999) demonstrated successful membrane sealing for persistent oligohydramnios after amniocentesis and fetoscopy, using intraamniotic injection of platelets and cryoprecipitate ("amniopatch") through a 22-gauge needle. Successful membrane sealing has been achieved with intrauterine injection of gelatin sponge ( $\mathrm{O}^{\prime}$ Brien et al., 2002). Sciscione and co-workers (2001) were able to achieve cessation of leakage and restoration of normal amniotic fluid volume in some women with intracervical instillation of fibrin sealants. However, the need for concurrent cervical cerclage placement to decrease fluid leakage has been described (Baumgarten \& Moser, 1986). Young and colleagues (Young et al., 2000, 2004a) demonstrated successful endoscopically guided sealing of an iatrogenic membrane defect using maternal platelets 
and fibrinogen/thrombin and subsequently demonstrated success with fibrin glue and powdered collagen slurry applied to puncture sites. While these studies, and other small case series, have raised the potential that membrane sealing can be performed effectively when the defect occurs in otherwise normal FM, further study regarding the optimal timing and method of intervention after iatrogenic PROM is needed.

Ultimately, because of the presence of antecedent membrane degradation and sub-clinical inflammation in the fetal membranes, membrane sealing may not be appropriate for those with spontaneous membrane rupture. It is not surprising that membranes that have ruptured as the result of having undergone extensive extracellular remodeling and cellular apoptosis may not readily reverse their physiological direction and repair themselves. Further study regarding the maternal/fetal risks and fetal benefits of invasive interventions for membrane rupture remote from term are warranted before such practices are incorporated into clinical practice. A detailed understanding of the process of physiological and pathological fetal membrane weakening may allow appropriate early intervention. Our models of in vitro tissue weakening with biochemical agents and stretch may prove useful in evaluating potential repair strategies.

\subsection{Prevention of weakening and rupture - Identification of at risk pregnancies}

If the potential for FM repair after rupture is limited, perhaps premature weakening of the fetal membranes can be prevented. To be medically and ethically acceptable, any procedure done on pregnant women to prevent possible FM weakening must be either totally innocuous or highly targeted toward women at significant risk for PPROM. In order to target women at risk they must first be reliably identified.

Spontaneous preterm birth due to preterm labor and PROM is associated with a variety of clinical characteristics and also with abnormal ancillary test findings (e.g. short cervix on transvaginal ultrasound, a positive cervicovaginal fetal-fibronectin screen) (Rangaswamy et al., 2011; Iams et al., 1996; Mercer et al., 1996; Goldenberg et al., 1996b). However, such evaluations are neither sensitive nor specific when applied to asymptomatic women, and there is significant overlap in the characteristics of women who ultimately deliver due to preterm labor and PROM (Mercer et al., 2000). As such, it remains difficult to identify those who will develop PROM before the fact. Recently, several groups have demonstrated that African Americans, a group with a high incidence of PPROM with early delivery, have a higher incidence of certain more active polymorphisms of MMPs and pro-inflammatory cytokines (Ferrand et al., 2002; Fujimoto et al., 2002; Hernandez-Guerrero et al., 2003; Roberts et al., 1999). It is possible that a combination of genes and historical factors could eventually lead to prediction of risk of PPROM with adequate certainty that procedures designed to prevent FM rupture that carry some inherent risk would be justifiable.

In the presence of minimal or no identified risk, administration of vitamin $C$ alone or in combination with vitamin $\mathrm{E}$ has been suggested for the prevention of PPROM, mainly for their antioxidant effect (Siega-Riz et al., 2003). However, there are concerns regarding the use of vitamin C as it can increase or decrease apoptosis (Orzechowski et al., 2002) depending on the cell system, dose, and co-effectors present. We have shown that vitamin $\mathrm{C}$ does not inhibit, and may exacerbate $\mathrm{H}_{2} \mathrm{O}_{2}$ induced apoptosis in amnion-derived WISH cells, amnion cell cultures, and amnion membrane explants (Kumar et al., 2004a, 2004b). In vivo studies have also shown mixed results with use of vitamin C. Although a single clinical trial of oral vitamin C demonstrated a decrease in PROM but not premature delivery, three much larger studies showed increased PROM and PPROM in the vitamin-supplemented 
groups (Spinnato et al., 2008; Hauth et al., 2010; Xu et al., 2010). Warnings were issued in these publications about use of vitamins $\mathrm{C} / \mathrm{E}$, at least at the doses utilized. Using our in vitro model of TNF-a-induced FM weakening, we have demonstrated that vitamin C preincubation does not prevent TNF-a induced FM weakness. In fact, high doses of vitamin C actually increase MMP-9 activity and weaken the FM.

\subsection{Alpha-Lipoic Acid (LA) inhibits cytokine and thrombin induced weakening}

In contrast, we have shown that Lipoic acid, a naturally occurring dietary supplement [routinely used as part of prophylaxis for diabetic neuropathy (Ziegler et al., 2009)], with anti-oxidant and NFkB inhibitory properties prevented TNF- $\alpha$ induced FM weakening and also prevented concomitant TNF-a induced increases in MMP-9 and PGE2 (Fig. 11.) [R.M. Moore et al, 2009]. The mechanism of Lipoic acid action is unclear but this effect on FM is not isolated. It has been shown to inhibit TNF- $\alpha$ induced NF- $\mathrm{kB}$ transcriptional activity and MMP-9 expression in vascular smooth muscle cells, and attenuate LPS-induced NF-KB: DNA-binding in monocytes by activating the PI3K/AKT pathway (Kim et al., 2007; Zhang et al., 2007). It also metabolically regenerates glutathione and other antioxidants (Bilska \& Wlodek et al., 2005). We have also demonstrated that LA inhibits FM weakening by Thrombin and inhibits Thrombin induced weakening of the isolated amnion (Kumar et al., 2011). As Lipoic acid inhibits both cytokine and thrombin induced FM weakening and remodeling, it is a promising candidate for possible clinical use to prevent PPROM. LA has been investigated in dozens of clinical trials (41 trials are now listed on clinicaltrials.gov) with no adverse effects reported. Unfortunately, all of the trials excluded pregnant women (Clinicaltrials.gov). There have also been promising toxicity studies in pregnant rats (Shirpoor A et al., 2008). A trial of LA in pregnant women at risk for PPROM awaits more definitive information of its mechanism of action in the prevention of FM weakening in addition to safety data.

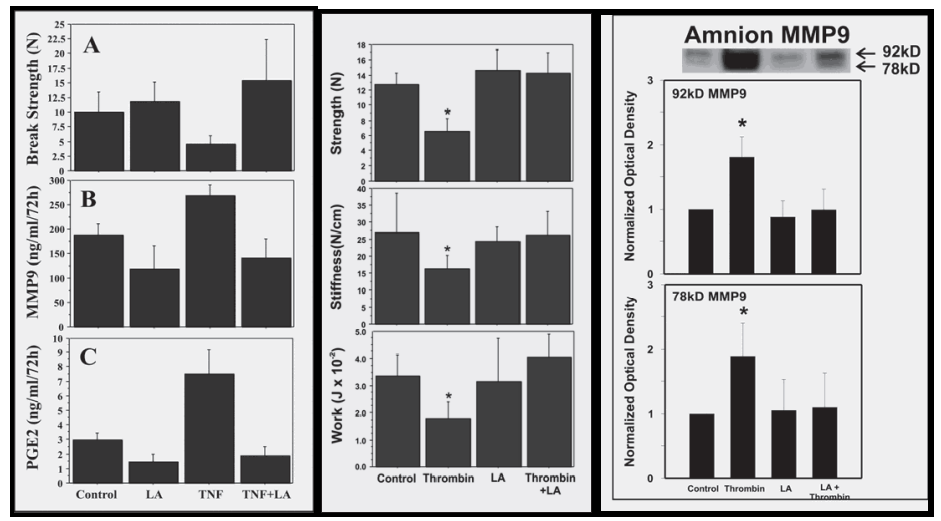

Fig. 11. Lipoic Acid inhibits TNF and Thrombin induced weakening and biochemical changes: [Left] TNF $(50 \mathrm{ng} / \mathrm{ml})$ induced weakening, increases in MMP9 and increases in PGE2 are inhibited by Lipoic Acid $(0.5 \mathrm{mM})$; [Middle] Thrombin $(10 \mathrm{U} / \mathrm{ml})$ induced changes in biomechanics are inhibited by lipoic acid $(.25 \mathrm{mM})$; [Right] Thrombin $(10 \mathrm{U} / \mathrm{ml})$ induced increases in MMP9 zymogen and active forms are inhibited by Lipoic Acid (.25 mM). Reproduced from Moore et al. Biol Reprod 80:781-87, 2009 and Placenta 31:886-892, 2010 with permission. 


\section{Conclusions}

It had been previously thought that the mechanical force due to uterine contraction during labor weakens the FM. This theory has been negated by the clinical fact that the FM rupture prior to the onset of contractions and by our finding that the force required to rupture the membranes is increased rather than decreased by cyclical mechanical stretching of FM in vitro. We have demonstrated that a weak zone develops in the FM overlying the cervix at the end of gestation. This weak zone is associated with collagen remodeling and apoptosis as evidenced by elevated MMP-9, decreased TIMP-3 and elevated PARP cleavage. Even though the process of weakening in term FM has been described, detailed molecular mechanisms and the initiating signals have yet to be unraveled. Our in vitro model system has facilitated demonstration that the weakening effect of cytokines (TNF- $\alpha$ and IL-1 $\beta$ ) and thrombin on FM results in collagen remodeling and apoptosis, similar to that observed in term FM delivered by unlabored cesarean and labored vaginal deliveries. Lipoic acid has been shown to inhibit the weakening effect of both these agents in vitro, suggesting that it could be a promising drug in the prevention of PPROM. However, studies are required to demonstrate its safety and efficacy in pregnant women.

\section{References}

Al-Zaid, N.S., Bou-Resli, M.N. \& Goldspink, G. (1980). Bursting pressure and collagen content of fetal membranes and their relation to premature rupture of the membranes,_Br J Obstet Gynaecol 87(3):227-229.

Arechavaleta-Velasco, F., Ogando, D., Parry, S. \& Vadillo-Ortega, F. (2002). Production of matrix metalloproteinase-9 in lipopolysaccharide-stimulated human amnion occurs through an autocrine and paracrine proinflammatory cytokine-dependent system, Biol Reprod 67(6):1952-1958.

Arikat, S., Novince, R., Kumar, D., Fox, J., Mercer, B., Mansour, J.M. \& Moore J.J. (2006). Separation of amnion from Choriodecidua is an integral event to the rupture of normal term fetal membranes and constitutes a significant proportion of the work required, Am J OB Gynecol. 194 (1):211-217.

Artal, R., Sokol, R.J., Neuman, M., Burstein, A.H. \& Stojkov, J. (1976). The mechanical properties of prematurely and non--prematurely ruptured membranes. Methods and preliminary results, Am J Obstet Gynecol. 125(5):655-659.

Athayde, N., Romero, R., Gomez, R., Maymon, E., Pacora, P., Mazor, M., Yoon, B.H., Fortunato, S., Menon, R., Ghezzi, F \& Edwin, S.S. (1999). Matrix metalloproteinases9 in preterm and term human parturition, J Matern Fetal Med. 8(5):213-219.

Athayde, N., Romero, R., Maymon, E., Gomez, R., Pacora, P., Yoon, B.H. \& Edwin, S.S. (2000). Interleukin 16 in pregnancy, parturition, rupture of fetal membranes, and microbial invasion of the amniotic cavity, Am J Obstet Gynecol. 182(1 Pt 1):135-141.

Bachmaier, N. \& Graf, R. (1999). The anchoring zone in the human placental amnion: bunches of oxytalan and collagen connect mesoderm and epithelium, Anat Embryol (Berl). 200(1):81-90.

Baergen, R., Benirschke, K. \& Ulich, T.R. (1994). Cytokine expression in the placenta. The role of interleukin 1 and interleukin 1 receptor antagonist expression in chorioamnionitis and parturition, Arch Pathol Lab Med. 118(1):52-55. 
Baumgarten, K. \& Moser, S. (1986). The technique of fibrin adhesion for premature rupture of the membranes during pregnancy, J Perinat Med. 14(1):43-49.

Behrman, R.E., Adashi, E.Y., Allen, M.C., Carouso, R.L et al. (2006). Preterm Birth: Causes, Consequences, Prevention, Report of the Institute of Medicine.

Beutler, B. (2004). Inferences, questions and possibilities in Toll-like receptor signaling, Nature. 430(6996):257-263.

Bilic, G., Brubaker, C., Messersmith, P.B., Mallik, A.S., Quinn, T.M., Haller, C., Done, E., Gucciardo, L., Zeisberger, S.M., Zimmermann, R., Deprest, J. \& Zisch, A.H. (2010). Injectable candidate sealants for fetal membrane repair: bonding and toxicity in vitro, Am J Obstet Gynecol. 202(1):85.e1-9

Bilska, A. \& Włodek, L. (2005). Lipoic acid - the drug of the future? Pharmacol Rep. 57(5):5707.

Boudreau, N., Sympson, C.J., Werb, Z. \& Bissell, M.J. (1995). Suppression of ICE and apoptosis in mammary epithelial cells by extracellular matrix, Science. 267(5199):891-893.

Bowen, J.M., Chamley, L., Keelan, J.A. \& Mitchell, M.D. (2002). Cytokines of the placenta and extra-placental membranes: roles and regulation during human pregnancy and parturition, Placenta. 23(4):257-273.

Bryant-Greenwood, G.D. \& Yamamoto, S.Y. (1995). Control of peripartal collagenolysis in the human chorion-decidua, Am J Obstet Gynecol. 172(1 Pt 1):63-70.

Bryant-Greenwood G.D., Kern, A., Yamamoto, S.Y., Sadowsky, D.W. \& Novy, M.J. (2007). Relaxin and the human fetal membranes, Reprod Sci. 14(8 Suppl):42-45.

Bryant-Greenwood, G.D., Yamamoto, S.Y., Sadowsky, D.W., Gravett, M.G. \& Novy, M.J. (2009). Relaxin stimulates interleukin-6 and interleukin-8 secretion from the extraplacental chorionic cytotrophoblast, Placenta. 30(7):599-606.

Buhimschi, I.A., Kramer, W.B., Buhimschi, C.S., Thompson, L.P. \& Weiner, C.P. (2000). Reduction-oxidation (redox) state regulation of matrix metalloproteinase activity in human fetal membranes, Am J Obstet Gynecol. 182(2):458-464.

Burguet, A., Kaminski, M., Abraham-Lerat, L., Schaal, J.P., Cambonie, G., Fresson, J., Grandjean, H., Truffert, P., Marpeau, L., Voyer, M., Rozé, J.C., Treisser, A. \& Larroque, B; EPIPAGE Study Group. (2004). The complex relationship between smoking in pregnancy and very preterm delivery, BJOG. 111(3):258-265.

Carta, G., Persia, G., Falciglia, K. \& Iovenitti, P. (2004). Periodontal disease and poor obstetrical outcome, Clin Exp Obstet Gynecol. 31(1):47-49.

Chang, C.J., Hsu, L.A., Ko, Y.H., Chen, P.L., Chuang, Y.T., Lin, C.Y., Liao, C.H. \& Pang, J.H. (2009). Thrombin regulates matrix metalloproteinase-9 expression in human monocytes, Biochemical and Biophysical Research Communications. 385(2):241-246.

Chintala, S.K., Zhang, X., Austin, J.S. \& Fini, M.E. (2002). Deficiency in matrix metalloproteinase gelatinase B (MMP-9) protects against retinal ganglion cell death after optic nerve ligation, J Biol Chem. 277(49):47461-47468.

Chua, W.K. \& Oyen, M.L. (2009). Do we know the strength of the chorioamnion? A critical review and analysis, Eur J Obstet Gynecol Reprod Biol. 144 Suppl 1:S128-33.

Connon, C.J., Nakamura, T., Hopkinson, A., Quantock, A., Yagi, N., Doutch, J. \& Meek, K.M. (2007). The biomechanics of amnion rupture: an X-ray diffraction study, PLoS One. 2(11):e1147. 
Cox, S.M., Casey, M.L. \& MacDonald, P.C. (1997). Accumulation of interleukin-1beta and interleukin-6 in amniotic fluid: a sequela of labour at term and preterm, Hum Reprod Update. 3(5):517-527.

Croy, B.A., Chantakru, S., Esadeg, S., Ashkar, A.A. \& Wei, Q. (2002). Decidual natural killer cells: key regulators of placental development (a review), J Reprod Immunol. 57(12):151-168.

Devlieger, R., Gratacos, E., Wu, J., Verbist, L., Pijnenborg, R. \& Deprest, J.A. (2000a). An organ-culture for in vitro fetal membrane healing capacity, Eur J Obstet Gynecol Reprod Biol. 92(1):145-150.

Devlieger, R., Deprest, J.A., Gratacós, E., Pijnenborg, R., Leask, R. \& Riley, S.C. (2000b). Matrix metalloproteinases -2 and -9 and their endogenous tissue inhibitors in fetal membrane repair following fetoscopy in a rabbit model, Mol Hum Reprod. 6(5):479485.

Devlieger, R., Ardon, H., Verbist, L., Gratacós, E., Pijnenborg, R. \& Deprest, J.A. (2003). Increased polymorphonuclear infiltration and iatrogenic amniotic band after closure of fetoscopic access sites with a bioactive membrane in the rabbit at midgestation, Am J Obstet Gynecol. 188(3):844-848.

Devlieger, R., Millar, L.K., Bryant-Greenwood, G., Lewi, L. \& Deprest, J.A. (2006). Fetal membrane healing after spontaneous and iatrogenic membrane rupture: a review of current evidence, Am J Obstet Gynecol. 195(6):1512-1520.

Diehl, S. \& Rincón, M. (2002). The two faces of IL-6 on Th1/Th2 differentiation, Mol Immunol. 39(9):531-536.

Dudley, D.J., Hunter, C., Varner, M.W \& Mitchell, M.D. (1996). Elevation of amniotic fluid interleukin-4 concentrations in women with preterm labor and chorioamnionitis, Am J Perinatol. 13(7):443-447.

El-Khwad, M., Stetzer, B., Moore, R.M., Kumar, D., Mercer, B., Arikat, S., Redline, R.W., Mansour, J.M. \& Moore, J.J. (2005). Pre-labor fetal membranes have a weak zone overlying the lower uterine pole and cervix, Biol Reprod. 72(3):720-726.

El-Khwad, M., Stetzer, B., Moore, R.M., Kumar, D., Arikat, S., Redline, R.W., Mansour, J.M. \& Moore, J.J. (2006). A circumscribed area along the tear line in human fetal membranes of vaginal deliveries demonstrates marked physical weakness and coincident evidence of apoptosis and remodeling, JSGI. 13(3):191-195.

Erez, O., Espinoza, J., Chaiworapongsa, T., Gotsch, F., Kusanovic, J.P., Than, N.G., MazakiTovi, S., Vaisbuch, E., Papp, Z., Yoon, B.H., Han, Y.M., Hoppensteadt, D., Fareed, J., Hassan, S.S. \& Romero, R. (2008). A link between a hemostatic disorder and preterm PROM: a role for tissue factor and tissue factor pathway inhibitor, J Matern Fetal Neonatal Med. 21(10):732-744.

Evaldson, G.R., Larsson, B. \& Jiborn, H. (1987). Is the collagen content reduced when the fetal membranes rupture? A clinical study of term and prematurely ruptured membranes, Gynecol Obstet Invest. 24(2):92-94.

Fabunmi, R.P., Baker, A.H., Murray, E.J., Booth, R.F. \& Newby, A.C. (1996). Divergent regulation by growth factors and cytokines of 95 and $72 \mathrm{kDa}$ gelatinases and tissue inhibitors or metalloproteinases- $-1,-2$, and -3 in rabbit aortic smooth muscle cells, Biochem. J. 315(Pt 1)335-342. 
Fang, Q., Liu, X., Al-Mugotir, M., Kobayashi, T., Abe, S., Kohyama, T. \& Rennard, S.I. (2006). Thrombin and TNF-alpha/IL-1beta synergistically Induce Fibroblast-Mediated Collagen Gel Degradation, Am J Respir Cell Mol Biol. 35(6):714-721.

Ferrand, P.E., Parry, S., Sammel, M., Macones, G.A., Kuivaniemi, H., Romero, R. \& Strauss III, J.F. (2002). A polymorphism in the matrix metalloproteinase- 9 promoter is associated with increased risk of preterm premature rupture of membranes in African Americans, Mol Hum Reprod. 8(5):494-501.

Fortunato, S.J., Menon, R., Swan, K.F. \& Lyden, T.W. (1994). Organ culture of amniochorionic membrane in vitro, Am J Reprod Immunol. 32(3):184-187.

Fortunato, S.J., Menon, R. \& Lombardi, S.J. (1999). MMP/TIMP imbalance in amniotic fluid during PROM: An indirect support for endogenous pathway to membrane rupture, J Perinat Med. 27(5):362-368.

Fortunato, S.J., Menon, R., Bryant, C. \& Lombardi, S.J. (2000). Programmed cell death (apoptosis) as a possible pathway to metalloproteinase activation and fetal membrane degradation in premature rupture of membranes, Am J Obstet Gynecol. 182(6):1468-1476.

Fortunato, S.J. \& Menon, R. (2001). Distinct molecular events suggest different pathways for preterm labor and premature rupture of membranes, Am J Obstet Gynecol. 184(7):1399-1405.

Fortunato, S.J., Menon, R. \& Lombardi, S.J. (2002). Role of tumor necrosis factor-alpha in the premature rupture of membranes and preterm labor pathways, Am J Obstet Gynecol. 187(5):1159-1162.

Fortunato, S.J. \& Menon, R. (2003). IL-1 beta is a better inducer of apoptosis in human fetal membranes than IL-6. Placenta. 24(10): 922-928.

Fujimoto, T., Parry, S., Urbanek, M., Sammel, M., Macones, G., Kuivaniemi, H., Romero, R. \& Strauss, J.F. 3rd. (2002). A single nucleotide polymorphism in the matrix metalloproteinase-1 (MMP-1) promoter influences amnion cell MMP-1 expression and risk for preterm premature rupture of the fetal membranes, J Biol Chem. 277(8):6296-6302.

Furuta, I., Yamada, H., Sagawa, T. \& Fujimoto, S. (2000). Effects of inflammatory cytokines on prostaglandin $\mathrm{E}(2)$ production from human amnion cells cultured in serum-free condition, Gynecol Obstet Invest. 49(2):93-97.

Garcia-Lloret, M.I., Yui, J., Winkler-Lowen, B. \& Guilbert, L.J. (1996). Epidermal growth factor inhibits cytokine-induced apoptosis of primary human trophoblasts, J Cell Physiol. 167(2):324-332.

Gearing, A.J., Beckett, P., Christodoulou, M., Churchill, M., Clements, J., Davidson, A.H, Drummond, A.H,, Galloway, W.A., Gilbert, R., Gordon, J.L., et al. (1994). Processing of tumour necrosis factor-alpha precursor by metalloproteinases, Nature. 370(6490):555-557.

Goldenberg, R.L., Mercer, B.M., Meis, P.J., Copper, R.L., Das, A. \& McNellis D. (1996b). The preterm prediction study: fetal fibronectin testing and spontaneous preterm birth. NICHD Maternal Fetal Medicine Units Network, Obstet Gynecol. 87(5 Pt 1):643-648.

Goldenberg, R.L., Cliver, S.P., Mulvihill FX, Hickey, C.A., Hoffman, H.J., Klerman, L.V. \& Johnson, M.J. (1996a). Medical, psychosocial, and behavioral risk factors do not explain the increased risk for low birth weight among black women, Am J Obstet Gynecol. 175(5):1317-1324. 
Goldenberg, R.L., Hauth, J.C. \& Andrews, W.W. (2000). Intrauterine infection and preterm delivery, N Engl J Med. 342(20):1500-1507.

Gunn, L., Hardiman, P., Tharmaratnam, S., Lowe, D. \& Chard, T. (1996). Measurement of interleukin-1 alpha and interleukin-6 in pregnancy-associated tissues, Reprod Fertil Dev. 8(7):1069-1073.

Haddad, R., Tromp, G., Kuivaniemi, H., Chaiworapongsa, T., Kim, Y.M., Mazor, M. \& Romero, R. (2006). Human spontaneous labor without histologic chorioamnionitis is characterized by an acute inflammation gene expression signature, Am J Obstet Gynecol. 195(2):394.e1-24.

Halaburt, J.T., Uldbjerg, N., Helmig, R. \& Ohlsson, K. (1989). The concentration of collagen and the collagenolytic activity in the amnion and the chorion, Eur J Obstet Gynecol Reprod Biol. 31(1):75-82.

Han YM, Romero R, Kim JS, Tarca AL, Kim SK, Draghici S, Kusanovic JP, Gotsch F, Mittal P, Hassan SS, Kim CJ. (2008). Region-specific gene expression profiling: novel evidence for biological heterogeneity of the human amnion. Biol Reprod. 79(5):95461.

Harger, J.H., Hsing, A.W., Tuomala, R.E., Gibbs, R.S., Mead, P.B. \& Eschenbach, D.A. (1990). Risk factors for preterm rupture of fetal membranes: a multicenter case-control study, Am J Obstet Gynecol. 163 (1 Pt 1):130-137.

Harmanli, O.H., Wapner, R.J. \& Lontz, J.F. (1998). Efficacy of fibrin glue for in vitro sealing of human chorioamniotic membranes, J Reprod Med. 43(11):986-990.

Hauth, J.C., Clifton, R.G., Roberts, J.M., Spong, C.Y., Myatt, L., Kenneth, J., et al for the Eunice Kennedy Shriver National Institute of Child Health and Human Development (NICHD) Maternal-Fetal Medicine Units Network (MFMU). Vitamin $\mathrm{C}$ and E Supplementation to Prevent Spontaneous Preterm Birth: A Randomized Controlled Trial, Obstet Gynecol. 2010; 116(3):653-658.

Heikkinen, J., Möttönen, M., Pulkki, K., Lassila, O. \& Alanen, A. (2001). Cytokine levels in midtrimester amniotic fluid in normal pregnancy and in the prediction of preeclampsia, Scand J Immunol. 53(3):310-314.

Hernandez-Guerrero, C., Monzon-Bordonaba, F., Jimenez-Zamudio, L., Ahued-Ahued, R., Arechavaleta-Velasco, F., Strauss, J.F. 3rd. \&Vadillo-Ortega, F. (2003). In-vitro secretion of proinflammatory cytokines by human amniochorion carrying hyperresponsive gene polymorphisms of tumour necrosis factor-alpha and interleukin1beta, Mol Hum Reprod. 9(10):625-629.

Hoebe, K., Janssen, E. \& Beutler, B. (2004). The interface between innate and adaptive immunity, Nat Immunol. 5(10):971-974.

Hollenberg, M.D. (2005). Physiology and Pathophysiology of Proteinase-Activated Receptors (PARs): Proteinases as Hormone-Like Signal Messengers: PARs and More, J Pharmacol Sci. 97(1):8-13.

Iams, J.D., Goldenberg, R.L., Meis, P.J., et al. (1996). The length of the cervix and the risk of spontaneous premature delivery: National Institute of Child Health and Human Development Maternal Fetal Medicine Unit Network, N Engl J Med. 334(9):567-572.

Jones, C.A., Finlay-Jones, J.J. \& Hart, P.H. (1997). Type-1 and type-2 cytokines in human lategestation decidual tissue, Biol Reprod. 57(2):303-311. 
Jones, H.E., Harris, K.A., Azizia, M., Bank, L., Carpenter, B., et al. (2009). Differing Prevalence and Diversity of Bacterial Species in Fetal Membranes from Very Preterm and Term Labor, PLoS One. 4(12): e8205.

Kayagaki, N., Kawasaki, A., Ebata, T., Ohmoto, H., Ikeda, S., Inoue, S., Yoshino, K., Okumura, K., Yagita, H. (1995). Metalloproteinase-mediated release of human Fas ligand, J Exp Med. 182(6):1777-1783.

Kim, H.S., Kim, H.J., Park, K.G., Kim, Y.N., Kwon, T.K., Park, J.Y., Lee, K.U., Kim, J.G., Lee, I.K. (2007). Alpha-lipoic acid inhibits matrix metalloproteinase-9 expression by inhibiting NF-kappaB transcriptional activity, Exp Mol Med. 39(1):106-113.

Kim, S.S., Romero, R., Kim, J.S., Abbas, A., Espinoza, J., Kusanovic, J.P., Hassan, S., Yoon, B.H. \& Kim, C.J. (2008). Coexpression of myofibroblast and macrophage markers: novel evidence for an in vivo plasticity of chorioamniotic mesodermal cells of the human placenta, Lab Invest. 88(4):365-374.

Kolev, K., Skopal, J., Simon, L., Csonka, E., Machovich, R. \& Nagy, Z. (2003). Matrix metalloproteinase-9 expression in post-hypoxic human brain capillary endothelial cells: $\mathrm{H} 2 \mathrm{O} 2$ as a trigger and NF-kappaB as a signal transducer, Thromb. Haemost. 90(3)528-537.

Kumar, D., Lundgren, D.W., Moore, R.M., Silver, R.J. \& Moore, J.J. (2004a). Hydrogen peroxide induced apoptosis in amnion-derived WISH cells is not inhibited by Vitamin C, Placenta. 25(4):266-272.

Kumar, D., Moore, R.M., El-khwad, M., Silver, R.J. \& Moore, J.J. (2004b). Vitamin C exacerbates hydrogen peroxide induced apoptosis and concomitant PGE2 release in amnion epithelial and mesenchymal cells and in intact amnion, Placenta. 25(6):573579.

Kumar, D., Fung, W., Moore, R.M., Pandey, V., Fox, J., Stetzer, B., Mansour, J.M., Mercer, B.M., Redline, R.W. \& Moore, J.J. (2006). Inflammatory mediators found in amniotic fluid induce collagen remodeling, apoptosis, and biophysical weakening of cultured fetal membranes, Biol Reprod. 74(1):29-34.

Kumar, D., Novince, R., Strohl, A., Mercer, B.M., Mansour, J.M., Moore, R.M. \& Moore, J.J. (2009). A new methodology to measure strength of adherence of the fetal membrane components, amnion and the choriodecidua, Placenta. 30(6):560-563.

Kumar, D., Schatz, F., Moore, R.M., Mercer, B.M., Rangaswamy, N., Mansour, J.M., Lockwood, C.J. \& Moore, J.J. (2011). The effects of Thrombin and Cytokines upon the Biomechanics and Remodeling of Isolated Amnion, In Vitro, Placenta. 2011. 32(3):206-213.

Ladfors, L., Mattsson, L.A., Eriksson, M. \& Milsom, I. (2000). Prevalence and risk factors for prelabor rupture of the membranes (PROM) at or nearterm in an urban Swedish population, J Perinat Med. 28(6):491-496.

Lafleur, M.A., Hollenberg, M.D., Atkinson, S.J., Knauper,.V., Murphy, G. \& Edwards, D.R. (2001). Activation of pro-(matrix metalloproteinase-2) (pro-MMP-2) by thrombin is membrane-type-MMP-dependent in human umbilical vein endothelial cells and generates a distinct $63 \mathrm{kDa}$ active species, Biochem. J. 357(Pt 1):107-115.

Laham, N., Brennecke, S.P., Bendtzen, K. \& Rice, G.E. (1994). Tumour necrosis factor alpha during human pregnancy and labour: maternal plasma and amniotic fluid concentrations and release from intrauterine tissues, Eur J Endocrinol. 131(6):607614 . 
Laham, N., Brennecke, S.P., Bendtzen, K. \& Rice GE. (1996). Differential release of interleukin-6 from human gestational tissues in association with labour and in vitro endotoxin treatment, J Endocrinol. 149(3):431-439.

Lappas M, Odumetse TL, Riley C, Reti NG, Holdsworth-Carson SJ, Rice GE, Permezel M. (2008). Pre-labour fetal membranes overlying the cervix display alterations in inflammation and NF-kappaB signalling pathways. Placenta. 29(12):995-1002.

Lappas, M., Riley, C., Rice, G.E. \& Permezel M. (2009). Increased Expression of ac-FoxO1 Protein in Prelabor Fetal Membranes Overlying the Cervix: Possible Role in Human Fetal Membrane Rupture, Reprod Sci. 16(7):635-641. 1.

Lappas M, Mitton A, Lim R, Barker G, Riley C, Permezel M. (2010a). SIRT1 is a novel regulator of key pathways of human labor. Biol Reprod. 84(1):167-178.

Lappas M, Lim R, Riley C, Menon R, Permezel M. (2010b). Expression and Localisation of FoxO3 and FoxO4 in Human Placenta and Fetal Membranes. Placenta 31:10431050.

Lavery, J.P. \& Miller, C.E. (1977). The viscoelastic nature of chorioamniotic membranes, Obstet Gynecol. 50(4):467-472.

Lavery, J.P. \& Miller, C.E. (1979). Deformation and creep in the human chorioamniotic sac. Am J Obstet Gynecol. 134(4):366-375.

Lavery, J.P., Miller, C.E. \& Knight, R.D. (1982). The effect of labor on the rheologic response of chorioamniotic membranes, Obstet Gynecol. 60(1):87-92.

Lee, T., Carpenter, M.W., Heber, W.W. \& Silver, H.M. (2003). Preterm premature rupture of membranes: risks of recurrent complications in the next pregnancy among a population-based sample of gravid women, Am J Obstet Gynecol. 188(1):209-213.

Lei, H., Vadillo-Ortega,,F., Paavola, L.G. \& Strauss, J.F. (1995). 92-kDa gelatinase (matrix metalloproteinase-9) is induced in rat amnion immediately prior to parturition, Biol Reprod. 53(2); 339-344.

Lei, H., Furth, E.E., Kalluri, R., Chiou, T., Tilly, K.I., Tilly, J.L., Elkon, K.B., Jeffrey, J.J. \& Strauss, J.F. 3rd. (1996). A program of cell death and extracellular matrix degradation is activated in the amnion before the onset of labor, J Clin Invest. 98(9):1971-1978.

Liu, W.H., Chen, X.M. \& Fu, B. (2000). Thrombin stimulates MMP-9 mRNA expression through AP-1 pathway in human mesangial cells, Acta Pharmacol. Sin. 21(7)641-645.

Liu, Y., Gilcrease, M.Z., Henderson, Y., Yuan, X.H., Clayman, G.L. \& Chen, Z. (2001). Expression of protease-activated receptor 1 in oral squamous cell carcinoma, Cancer Lett. 169(2)173-180.

Locksmith, G.J., Clark, P., Duff, P., Saade, G.R. \& Schultz, G.S. (2001). Amniotic fluid concentrations of matrix metalloproteinase 9 and tissue inhibitor of metalloproteinase 1 during pregnancy and labor, Am J Obstet Gynecol. 184(2):159164.

Lockwood, C.J., Nemerson, Y., Guller, S., Krikun, G., Alvarez, M., Hausknecht, V., Gurpide, E. \& Schatz, F. (1993). Progestational regulation of human endometrial stromal cell tissue factor expression during decidualization, J Clin Endocrinol Metab. 76(1):231236.

Lockwood, C.J. \& Kuczynski, E. (1999). Markers of risk for preterm delivery, J Perinat Med. 27(1):5-20. 
Lockwood, C.J., Krikun, G., Schatz, F. (2001). Decidual cell-expressed tissue factor maintains hemostasis in human endometrium, Ann NY Acad Sci. 943:77-88

Lockwood, C.J., Oner, C., Uz, Y.H., Kayisli, U.A., Huang, S.J., Buchwalder, L.F., Murk, W., Funai, E.F. \& Schatz, F. (2008). Matrix metalloproteinase 9 (MMP9) expression in preeclamptic deciduas and MMP9 induction by tumor necrosis factor alpha and interleukin 1 beta in human first trimester decidual cells, Biol Reprod. 78(6):1064-1072.

Louis-Sylvestre, C., Rand, J.H., Gordon, R.E., Salafia, C.M. \& Berkowitz, R.L. (1998). In vitro studies of the interactions between platelets and amniotic membranes: a potential treatment for preterm premature rupture of the membranes, Am J Obstet Gynecol. 178(2):287-293.

Lundin-Schiller, S. \& Mitchell, M.D. (1991). Prostaglandin production by human chorion laeve cells in response to inflammatory mediators, Placenta. 12(4):353-363.

Lyons, C.A., Beharry, K.D., Nishihara, K.C., Akmal, Y., Ren, Z.Y., Chang, E., Nageotte, M.P. (2002). Regulation of matrix metalloproteinases (type IV collagenases) and their inhibitors in the virgin, timed pregnant, and postpartum rat uterus and cervix by prostaglandin E(2)-cyclic adenosine monophosphate, Am J Obstet Gynecol. 187(1):202-208.

MacDorman, M.F. \& Mathews, T.J. (2008). Recent Trends in Infant Mortality in the United States, NCHS Data Brief. (9):1-8.

Malak, T.M. \& Bell, S.C. (1994). Structural characteristic of term human fetal membranes: a novel zone of extreme morphological alteration within the rupture site, $\mathrm{Br} J$ Obstet Gynecol. 101(5):375-386.

Manabe, Y., Himeno, N. \& Fukumoto, M. (1991). Tensile strength and collagen content of amniotic membrane do not change after the second trimester or during delivery, Obstet Gynecol. 78(1):24-27.

Mannello, F. \& Gazzanelli, G. (2001). Tissue inhibitors of metalloproteinases and programmed cell death: conundrums, controversies and potential implications, Apoptosis. 6(6):479-482.

Maymon, E., Ghezzi, F., Edwin, S.S., Mazor, M., Yoon, B.H., Gomez, R. \& Romero, R. (1999). The tumor necrosis factor alpha and its soluble receptor profile in term and preterm parturition, Am J Obstet Gynecol. 181(5 Pt 1):1142-1148.

Maymon, E., Romero, R., Pacora, P., Gomez, R., Mazor, M., Edwin, S., Chaiworapongsa, T., Kim, J.C., Yoon, B.H., Menon, R., Fortunato, S. \& Berry, S.M. (2001). A role for the $72 \mathrm{kDa}$ gelatinase (MMP-2) and its inhibitor (TIMP-2) in human parturition, premature rupture of membranes and intraamniotic infection, $J$ Perinat Med. 29(4):308-316.

McLaren, J., Malak, T.M. \& Bell, S.C. (1999a). Structural characteristics of term human fetal membranes prior to labour: identification of an area of altered morphology overlying the cervix, Hum Reprod. 14(1):237-241.

McLaren, J., Taylor, D.J. \& Bell, S.C. (1999b). Increased incidence of apoptosis in non-labour -affected cytotrophoblast cells in term fetal membranes overlying the cervix, Human Reprod. 14(1):2895-2900.

McLaren, J., Taylor, D.J. \& Bell, S.C. (2000a). Increased concentration of pro-matrix metalloproteinase 9 in term fetal membranes overlying the cervix before labor: implications for membrane remodeling and rupture, Am J Obstet Gynecol. 182(2):409-416. 
McLaren, J., Taylor, D.J. \& Bell, S.C. (2000b). Prostaglandin E(2)-dependent production of latent matrix metalloproteinase-9 in cultures of human fetal membranes, Mol Hum Reprod. 6(11):1033-1040.

McParland, P.C., Taylor, D.J. \& Bell, S.C. (2003). Mapping of zones of altered morphology and chorionic connective tissue cellular phenotype in human fetal membranes (amniochorion and decidua) overlying the lower uterine pole and cervix before labor at term, Am J Obstet Gynecol. 189(5):1481-1488.

Meinert, M., Eriksen, G.V., Petersen, A.C., Helmig, R.B., Laurent, C., Uldbjerg, N. \& Malmström, A. (2001). Proteoglycans and hyaluronan in human fetal membranes, Am J Obstet Gynecol. 184(4):679-685.

Meinert, M., Malmström, A., Tufvesson, E., Westergren-Thorsson, G., Petersen, A.C., Laurent, C., Uldbjerg, N., Eriksen, G.V. (2007). Labour induces increased concentrations of biglycan and hyaluronan in fetal membranes, Placenta. 28(56):482-486.

Mendoza, G.A., Acuña, E., Allen, M., Arroyo, J. \& Quintero, R.A. (1999). In vitro laser welding of amniotic membranes, Lasers Surg Med. 24(5):315-318.

Menon, R. \& Fortunato, S.J. (2004). The role of matrix degrading enzymes and apoptosis in rupture of membranes, J Soc Gynecol Investig. 11(7):427-437.

Mercer, B.M., Goldenberg, R.L., Das, A., Moawad, A.H., Iams, J.D., Meis, P.J., Copper, R.L., Johnson, F., Thom, E., McNellis, D., Miodovnik, M., Menard, M.K., Caritis, S.N., Thurnau, G.R., Bottoms, S.F. \& Roberts, J. (1996). The preterm prediction study: a clinical risk assessment system, Am J Obstet Gynecol. 174(6):1885-1893; discussion 1893-1895.

Mercer, B.M., Goldenberg, R.L., Moawad, A.H., Meis, P.J., Iams, J.D., Das, A.F., Caritis, S.N., Miodovnik, M., Menard, M.K., Thurnau, G.R., Dombrowski, M.P., Roberts, J.M. \& McNellis, D. (1999). The preterm prediction study: effect of gestational age and cause of preterm birth on subsequent obstetric outcome. National Institute of Child Health and Human Development Maternal-Fetal Medicine Units Network, Am J Obstet Gynecol. 181(5 Pt 1):1216-1221.

Mercer, B.M., Goldenberg, R.L., Meis, P.J., Moawad, A.H., Shellhaas, C., Das, A., Menard, M.K., Caritis, S.N., Thurnau, G.R., Dombrowski, M.P., Miodovnik, M., Roberts, J.M., McNellis, D. (2000). The Preterm Prediction Study: prediction of preterm premature rupture of membranes through clinical findings and ancillary testing. The National Institute of Child Health and Human Development Maternal-Fetal Medicine Units Network, Am J Obstet Gynecol. 183(3):738-745.

Mercer, B.M., Abdelrahim, A., Moore, R.M., Novak, J., Kumar, D., Mansour, J.M., PerezFournier, M., Milluzzi, C. \& Moore, J.J. (2010). The impact of Vitamin C supplementation in pregnancy and in-vitro upon fetal membrane strength and remodeling, Reprod Sciences. 17(7):685-695.

Millar, L.K., Boesche, M.H., Yamamoto, S.Y., Killeen, J., DeBuque, L., Chen, R. \& BryantGreenwood, G.D. (1998). A relaxin-mediated pathway to preterm premature rupture of the fetal membranes that is independent of infection, Am J Obstet Gynecol. 179(1):126-134.

Millar, L.K., Reiny, R., Yamamoto, S.Y., Okazaki, K., Webster, L. \& Bryant-Greenwood, G.D. (2003). Relaxin causes proliferation of human amniotic epithelium by stimulation of insulin-like growth factor-II, Am J Obstet Gynecol. 188(1):234-241. 
Moore, A.G., Brown, D.A., Fairlie, W.D., Bauskin, A.R., Brown, P.K., Munier, M.L., Russell, P.K., Salamonsen, L.A., Wallace, E.M. \& Breit, S.N. (2000). The transforming growth factor-ss superfamily cytokine macrophage inhibitory cytokine-1 is present in high concentrations in the serum of pregnant women, J Clin Endocrinol Metab. 85(12):4781-4788.

Moore, J.J., Dubyak, G., Moore, R. \& Vander Kooy D. (1988). Oxytocin activates the inostisolphospholipid - protein kinase $C$ system and stimulates prostaglandin production in human amnion cells, Endocrinology. 123(4):1771-1777.

Moore, J.J., Moore, R.M., Collins, P.L. (1993). Protein kinase A activators inhibit agonist induced prostaglandin production in human amnion cells, Prostaglandins Leukotrienes and Essential Fatty Acids. 48(5):355-361.

Moore, R.M., Mansour, J.M., Redline, R., Mercer, B.M. \& Moore, J.J. (2006). The physiology of fetal membrane rupture: insight gained from the determination of physical properties, Placenta. 27(11-12):1037-1051.

Moore, R.M., Redline, R.W., Kumar, D., Mercer, B.M., Mansour, J.M., Yohannes, E., Novak, J.B., Chance, M.R., Moore, J.J. (2009a). Differential expression of fibulin family proteins in the para-cervical weak zone and other areas of human fetal membranes, Placenta. 30(4):335-341.

Moore, R.M., Novak, J.B., Kumar, D., Mansour, J.M., Mercer, B.M. \& Moore, J.J. (2009b). Alpha-lipoic acid inhibits Tumor Necrosis Factor-induced remodeling and weakening of human fetal membranes, Biol Reprod. 80(4):781-787.

Moore, R.M., Schatz, F., Kumar, D., Mercer, B.M., Rangaswamy, N., Abdelrahim, A., Bartel, C., Mansour, J.M., Lockwood, C.J. \& Moore JJ. (2010). Alpha-Lipoic Acid Inhibits Thrombin-Induced Fetal Membrane Weakening In Vitro, Placenta. 31(10):886-892.

O'Brien, J.M., Mercer, B.M., Barton, J.R. \& Milligan, D.A. (2001). An in vitro model and case report that used gelatin sponge to restore amniotic fluid volume after spontaneous premature rupture of the membranes, Am J Obstet Gynecol. 185(5):1094-1097.

O'Brien, J.M., Barton, J.R. \& Milligan, D.A. (2002). An aggressive interventional protocol for early midtrimester premature rupture of the membranes using gelatin sponge for cervical plugging, Am J Obstet Gynecol. 187(5):1143-1146.

Offenbacher, S., Boggess, K.A., Murtha AP, et al. (2006). Progressive periodontal disease and risk of very preterm delivery, Obstet Gynecol. 107(1):29-36.

Opsjłn, S.L., Wathen, N.C., Tingulstad, S., Wiedswang, G., Sundan, A., Waage, A. \& Austgulen, R. (1993). Tumor necrosis factor, interleukin-1, and interleukin-6 in normal human pregnancy. Am J Obstet Gynecol. 169(2 Pt 1):397-404.

Orzechowski, A., Łokociejewska, M., Muras, P. \& Hocquette, J.F. (2002). Preconditioning with millimolar concentrations of vitamin $\mathrm{C}$ or N-acetylcysteine protects L6 muscle cells insulin-stimulated viability and DNA synthesis under oxidative stress, Life Sci. 71(15):1793-1808.

Osman, I., Young, A., Jordan, F., Greer, I.A. \& Norman, J.E. (2006). Leukocyte density and proinflammatory mediator expression in regional human fetal membranes and decidua before and during labor at term, J Soc Gynecol Investig. 13(2):97-103.

Osmers, R.G.W., Blaser, J., Kuhn, W. \& Tschesche, H. (1995). Interleukin-8 synthesis and the onset of labor, Obstet. Gynecol. 86(2):223-229.

Ossovskaya, V.S. \& Bunnett, N.W. (2004). Protease-Activated Receptors: Contribution to Physiology and Disease, Physiol Rev. 84(2): 579-621. 
Paavola, L.G., Furth, E.E., Delgado, V., Boyd, C.O., Jacobs, C.C., Lei, H., Strauss, J.F.3rd. (1995). Striking changes in the structure and organization of rat fetal membranes precede parturition, Biol Reprod. 53(2):321-338.

Pandey, V., Jaremko, K., Moore, R.M., Mercer, B., Stetzer, B., Kumar, D., Fox, J., Mansour, J., Moore, J.J. (2007). The force required to rupture fetal membranes paradoxically increases with acute in vitro repeated stretching, Am J OB Gynecol. 196(2):165.e1-7.

Parry, S. \& Strauss, J.F. (1998). Premature rupture of the fetal membranes, N Engl J Med. 338(10):663-670.

Pressman, E.K., Cavanaugh, J.L. \& Woods, J.R. (2002). Physical properties of the chorioamnion throughout gestation, Am J Obstet Gynecol. 187(3):672-675.

Quintero, R.A., Morales, W.J., Kalter, C.S., Allen, M., Mendoza, G., Angel, J.L. \& Romero, R. (1998). Transabdominal intra-amniotic endoscopic assessment of previable premature rupture of membranes, Am J Obstet Gynecol. 179(3):71-76.

Quintero, R.A., Morales, W.J., Allen, M., Bornick, P.W., Arroyo, J. \& LeParc, G. (1999). Treatment of iatrogenic previable premature rupture of membranes with intraamniotic injection of platelets and cryoprecipitate (amniopatch): preliminary experience, Am J Obstet Gynecol. 181(3):744-749.

Ramachandran, R. and Hollenberg, M.D. (2008). Proteinases and signaling: pathophysiological and therapeutic implications via PARs and more, British Journal of Pharmacology. 153, S263-S282

Rangaswamy, N., Abdelrahim, A., Moore, R.M., Uyen, L., Mercer, B.M., Mansour, J.M., Kumar, D., Sawady, J. \& Moore, J.J. (2011). Biomechanical characteristics of human fetal membranes. Preterm fetal membranes are stronger than term fetal membranes. Gynecol Obstet Fertil. 39(6):373-377.

Reddy, U.M., Shah, S.S., Nemiroff, R.L., Ballas, S.K., Hyslop, T., Chen, J., Wapner, R.J., Sciscione, A.C. (2001). In vitro sealing of punctured fetal membranes: potential treatment for midtrimester premature rupture of membranes, Am J Obstet Gynecol. 185(5):1090-1093.

Reti, N.G., Lappas, M., Riley, C., Wlodek, M.E., Permezel,.M., Walker, S. \& Rice, G.E. (2007). Why do membranes rupture at term? Evidence of increased cellular apoptosis in the supracervical fetal membranes, Am J Obstet Gynecol. 196(5):484.e1-10.

Riley, S.C., Leask, R., Chard, T., Wathen, N.C., Calder, A.A. \& Howe, D.C. (1999). Secretion of matrix metalloproteinase-2, matrix metalloproteinase- 9 and tissue inhibitor of matrix metalloproteinases into the intrauterine compartments during early pregnancy, Mol Hum Reprod. 5(4):376-381.

Roberts, A.K., Monzon-Bordonaba, F., Van Deerlin, P.G., Holder, J., Macones, G.A., Morgan, M.A., Strauss, J.F. 3rd. \& Parry, S. (1999). Association of polymorphism within the promoter of the tumor necrosis factor alpha gene with increased risk of preterm premature rupture of the fetal membranes, Am J Obstet Gynecol. 180(5):1297-1302.

Romero, R., Mazor, M., Wu, Y.K., Sirtori, M., Oyarzun, E., Mitchell, M.D. \& Hobbins, J.C. (1988). Infection in the pathogenesis of preterm labor. Semin Perinatol. 12(4):262-279.

Romero, R., Parvizi, S.T., Oyarzun, E., Mazor, M., Wu, Y.K., Avila, C., Athanassiadis, A.P. \& Mitchell, M.D. (1990a). Amniotic fluid interleukin-1 in spontaneous labor at term, $J$ Reprod Med. 35(3):235-238.

Romero, R., Avila, C., Santhanam, U. \& Sehgal, P.B. (1990b). Amniotic fluid interleukin 6 in preterm labor. Association with infection, J Clin Invest. 85(5):1392-1400. 
Romero, R., Mazor, M., Sepulveda, W., Avila, C., Copeland, D. \& Williams, J. (1992a). Tumor necrosis factor in preterm and term labor, Am J Obstet Gynecol. 166(5):1576-1587.

Romero, R., Sepulveda, W., Mazor, M., Brandt, F., Cotton, D.B., Dinarello, C.A. \& Mitchell, M.D. (1992b). The natural interleukin-1 receptor antagonist in term and preterm parturition, Am J Obstet Gynecol. 167(4 Pt 1):863-872.

Romero, R., Baumann, P., Gomez, R., Salafia, C., Rittenhouse, L., Barberio, D., Behnke, E., Cotton, D.B. \& Mitchell, M.D. (1993). The relationship between spontaneous rupture of membranes, labor, and microbial invasion of the amniotic cavity and amniotic fluid concentrations of prostaglandins and thromboxane B2 in term pregnancy, Am J Obstet Gynecol. 168(6 Pt 1):1654-1664.

Runić, R., Lockwood, C.J., LaChapelle, L., Dipasquale, B., Demopoulos, R.I., Kumar, A. \& Guller, S. (1998). Apoptosis and Fas expression in human fetal membranes, J Clin Endocrinol Metab. 83(2):660-666.

Rusterholz, C., Hahn, S. \& Holzgreve, W. (2007). Role of placentally produced inflammatory and regulatory cytokines in pregnancy and the etiology of preeclampsia, Semin Immunopathol. 29(2):151-162.

Sağol, S., Sağol, O., Ozkal, S. \& Asena, U. 2002. Role of apoptosis, bcl-2 and bax protein expression in premature rupture of fetal membranes, J Reprod Med. 47(10):809815.

Salafia CM, Lopez-Zeno JA, Sherer DM, Whittington SS, Minior VK, Vintzileos AM et al. Histologic evidence of old intrauterine bleeding is more frequent in prematurity. Am J Obstet Gynecol. 1995; 173:1065-1070.

Sciscione, A.C., Manley, J.S., Pollock, M., Maas, B., Shlossman, P.A., Mulla, W., Lankiewicz, M. \& Colmorgen, G.H. (2001). Intracervical fibrin sealants: A potential treatment for early preterm premature rupture of the membranes, Am J Obstet Gynecol. 184(3):368-373.

Shen, T.T., DeFranco, E.A., Stamilio, D.M., Chang, J.J. \& Muglia, L.J. (2008). A populationbased study of race-specific risk for preterm premature rupture of membranes, Am J Obstet Gynecol. 199:373.e1-7.

Shirpoor, A., Minassian, S., Salami, S., Khadem-Ansari, M.H. \& Yeghiazaryan, M. (2008). Alpha--lipoic acid decreases DNA damage and oxidative stress induced by alcohol in the developing hippocampus and cerebellum of rat, Cell Physiol Biochem. 22(56):769-776.

Siega-Riz, A.M., Promislow, J.H., Savitz, D.A., Thorp, J.M. Jr. \& McDonald, T. (2003). Vitamin C intake and the risk of preterm delivery, Am J Obstet Gynecol. 189(2):519525.

Simhan, H.N., Krohn, M.A., Roberts, J.M., Zeevi, A. \& Caritis, S.N. (2003). Interleukin-6 promoter -174 polymorphism and spontaneous preterm birth, Am J Obstet Gynecol. 189(4):915-918.

So, T., Ito, A., Sato, T., Mori, Y., Hirakawa, S. (1992). Tumor necrosis factor-alpha stimulates the biosynthesis of matrix metalloproteinases and plasminogen activator in cultured human chorionic cells, Biol Reprod. 46(5):772-778.

Spinnato, J.A. II., Freire, S., Pinto e Silva, J.L., et al. Antioxidant supplementation and premature rupture of the membranes: a planned secondary analysis, Am J Obstet Gynecol. 2008; 199(4):433.e1-8. 
Strohl, A., Kumar, D., Novince, R., Shaniuk, P., Smith, J., Bryant, K., Moore, R.M., Novak, J., Stetzer, B., Mercer, B.M., Mansour, J.M. \& Moore, J.J. (2010). Decreased Adherence and Spontaneous Separation of Fetal Membrane Layers--Amnion and Choriodecidua - a Possible Part of the Normal Weakening Process, Placenta. 31(1): 18-24.

Stuart, E.L., Evans, G.S., Lin, Y.S. \& Powers, H.J. (2005). Reduced collagen and ascorbic acid concentrations and increased proteolytic susceptibility with prelabor fetal membrane rupture in women, Biol Reprod. 72(1):230-235.

Thomakos, N., Daskalakis, G., Papapanagiotou, A., Papantoniou, N., Mesogitis, S. \& Antsaklis, A. (2010). Amniotic fluid interleukin-6 and tumor necrosis factor-a at mid-trimester genetic amniocentesis: Relationship to intra-amniotic microbial invasion and preterm delivery, European Journal of Obstetrics $\mathcal{E}$ Gynecology and Reproductive Biology. 148(2):147-151.

Toppozada, M.K., Sallam, N.A., Gaafar, A.A., el-Kashlan, K.M. (1970). Role of repeated stretching in the mechanism of timely rupture of the membranes, Am J Obstet Gynecol. 108(2):243-249.

Ugwumadu, A.H. (2002). Bacterial vaginosis in pregnancy, Curr Opin Obstet Gynecol. 14(2):115-118.

Ulug, U., Goldman, S., Ben-Shlomo, I., Shalev, E. (2001). Matrix metalloproteinase (MMP)-2 and MMP-9 and their inhibitor, TIMP-1, in human term decidua and fetal membranes: the effect of prostaglandin F(2alpha) and indomethacin, Mol Hum Reprod. 7(12):1187-1193.

Vadillo-Ortega, F., Sadowsky, D.W., Haluska, G.J., Hernandez-Guerrero, C., Guevara-Silva, R., Gravett, M.G. \& Novy, M.J. (2002). Identification of matrix metalloproteinase-9 in amniotic fluid and amniochorion in spontaneous labor and after experimental intrauterine infection or interleukin-1b infusion in pregnant rhesus monkeys, $A m \mathrm{~J}$ Obstet Gynecol 186(1):128-138.

Wang, L., Luo, J. \& He, S. (2007). Induction of MMP-9 release from human dermal fibroblasts by thrombin: involvement of JAK/STAT3 signaling pathway in MMP-9 release, BMC Cell Biol 8:14.

Werner, S.L., Barken, D. \& Hoffmann, A. (2005). Stimulus specificity of gene expression programs determined by temporal control of IKK activity, Science 309(5742):18571861.

Xu, P., Alfaidy, N. \& Challis, J.R. (2002). Expression of matrix metalloproteinase (MMP)-2 and MMP-9 in human placenta and fetal membranes in relation to preterm and term labor, J Clin Endocrinol Metab 87(3):1353-1361.

Xu, H., Perez-Cuevas, R., Xiong X, et al. (2010). An international trial of antioxidants in the prevention of preeclampsia (INTAPP). Am J Obstet Gynecol 202(3):239.e1-10.

Yoshida, M., Sagawa, N., Itoh, H., Yura, S., Takemura, M., Wada, Y., Sato, T., Ito, A. \& Fujii, S. (2002). Prostaglandin F (2alpha), cytokines and cyclic mechanical stretch augment matrix metalloproteinase-1 secretion from cultured human uterine cervical fibroblast cells, Mol Hum Reprod 8(7):681-7.

Young, A., Thomson, A.J., Ledingham, M., Jordan, F., Greer, I.A. \& Norman, J.E. (2002). Immunolocalization of proinflammatory cytokines in myometrium, cervix, and fetal membranes during human parturition at term, Biol Reprod 66(2):445-449. 
Young, B.K., Roque, H., Abdelhak, Y.E., Poiolek, D., Demopulos, R. \& Lockwood, C.J. (2000). Minimally invasive endoscopy in the treatment of preterm premature rupture of membranes by application of fibrin sealant, J Perinat Med 28(4):326-330.

Young, B.K., Roman, A.S., MacKenzie, A.P., Stephenson, C.D., Minior, V., Rebarber, A. \& Timor-Tritsch, I. (2004a). The closure of iatrogenic membrane defects after amniocentesis and endoscopic intrauterine procedures, Fetal Diagn Ther 19(3):296300.

Young, B.K., MacKenzie, A.P., Roman, A.S., Stephenson, C.D., Minior, V., Rebarber, A. \& Timor-Tritsch, I. (2004b). Endoscopic closure of fetal membrane defects: comparing iatrogenic versus spontaneous rupture cases, J Matern Fetal Neonatal Med 16(4):235240.

Yuan, B., Ohyama, K., Takeichi, M. \& Toyoda, H. (2009). Direct contribution of inducible nitric oxide synthase expression to apoptosis induction in primary smooth chorion trophoblast cells of human fetal membrane tissues, Int J Biochem Cell Biol 41(5):10621069.

Zaga, V., Estrada-Gutierrez, G., Beltran-Montoya, J., Maida-Claros, R., Lopez-Vancell, R. \& Vadillo-Ortega, F. (2004). Secretions of interleukin-1beta and tumor necrosis factor alpha by whole fetal membranes depend on initial interactions of amnion or choriodecidua with lipopolysaccharides or group B streptococci, Biol Reprod 71(4):1296-1302.

Zhang, W.J., Wei, H., Hagen, T. \& Frei, B. (2007). Alpha-lipoic acid attenuates LPS-induced inflammatory responses by activating the phosphoinositide 3-kinase/Akt signaling pathway, Proc Natl Acad Sci U S A 104(10):4077-4082.

Ziegler, D. (2009). Painful diabetic neuropathy: Advantage of novel drugs over old drugs, Diabetes Care 32:S414-419. 


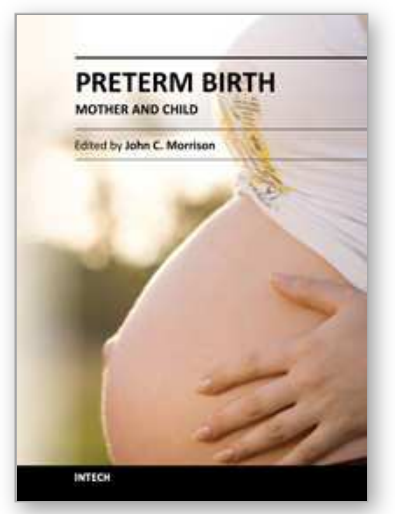

\author{
Preterm Birth - Mother and Child \\ Edited by Dr. John Morrison
}

ISBN 978-953-307-828-1

Hard cover, 368 pages

Publisher InTech

Published online 27, January, 2012

Published in print edition January, 2012

While there are many studies and books regarding preterm birth, both the obstetric and in the neonatal/pediatric literature, what is missing is the integration of data from obstetrics through neonatal course and into pediatrics as the neonate transverses childhood. A continued dialogue between specialties is essential in the battle against preterm birth in an attempt to relieve the effects or after-effects of preterm birth. For all of our medical advances to date, preterm birth is still all too common, and its ramifications are significant for hospitals, families and society in general.

\title{
How to reference
}

In order to correctly reference this scholarly work, feel free to copy and paste the following:

N. Rangaswamy, D. Kumar, R.M. Moore, B.M. Mercer, J.M. Mansour, R. Redline and J.J. Moore (2012). Weakening and Rupture of Human Fetal Membranes - Biochemistry and Biomechanics, Preterm Birth Mother and Child, Dr. John Morrison (Ed.), ISBN: 978-953-307-828-1, InTech, Available from: http://www.intechopen.com/books/preterm-birth-mother-and-child/weakening-and-rupture-of-human-fetalmembranes-biochemistry-and-biomechanics

\section{INTECH}

open science | open minds

\section{InTech Europe}

University Campus STeP Ri Slavka Krautzeka 83/A 51000 Rijeka, Croatia Phone: +385 (51) 770447

Fax: +385 (51) 686166 www.intechopen.com

\section{InTech China}

Unit 405, Office Block, Hotel Equatorial Shanghai No.65, Yan An Road (West), Shanghai, 200040, China 中国上海市延安西路65号上海国际贵都大饭店办公楼405单元 Phone: +86-21-62489820

Fax: $+86-21-62489821$ 
(C) 2012 The Author(s). Licensee IntechOpen. This is an open access article distributed under the terms of the Creative Commons Attribution 3.0 License, which permits unrestricted use, distribution, and reproduction in any medium, provided the original work is properly cited. 